\title{
Stress
}

\section{Clinical and Developmental Aspects of Salivary Cortisol in Infants}

Katrin Ivars

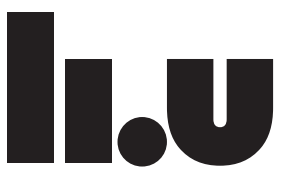

LINKÖPING UNIVERSITY

Department of Pediatrics

Department of Clinical and Experimental Medicine (IKE)

Faculty of Health Sciences, Linköping University

SE-581 85 Linköping, Sweden

Linköping 2016 
(C) Katrin Ivars, 2016

Cover: A sketch of Pontus. Made by the author.

Previously published material has been reprinted with permission from the respective copyright holders. All illustrations are made by the author.

Linköping University Medical Dissertations No. 1516

ISBN: 978-91-7685-805-9

ISSN: 0345-0082

Printed in Sweden by LiU-Tryck, Linköping, Sweden, 2016. 
I would like to dedicate this thesis

\section{To Pontus and Victor}

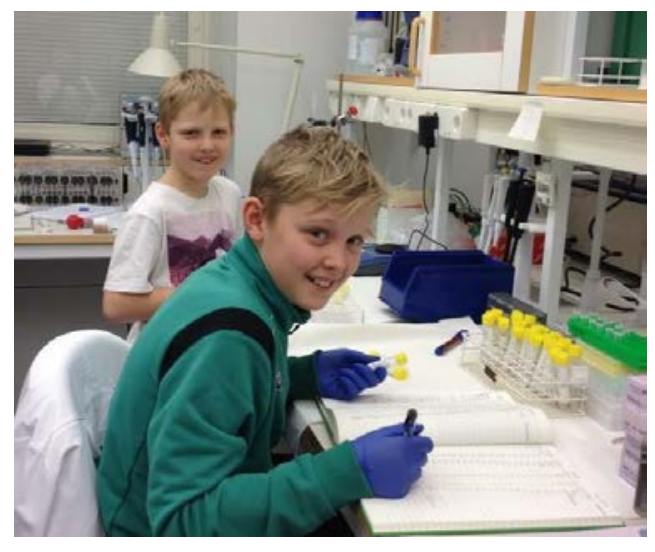

Thank you for your LOVE, HELP and SUPPORT!!

Without you hugs, kind words and laughter I would not be standing here...

Love, Stress and Health, All Essentials for Life

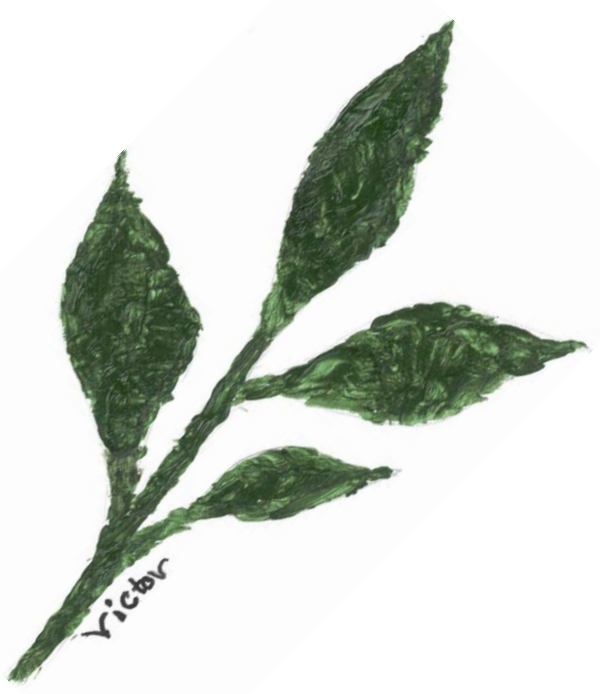

"I don't know where I'm going from here but I promise it won't be boring" David Bowie 


\section{SUPERVISOR}

Nina Nelson-Follin, Professor

Department of Pediatrics and Department of Clinical and Experimental Medicine Linköping University

Linköping, Sweden

Department of Quality and Patient Safety

Karolinska University Hospital

Stockholm, Sweden

\section{ASSISTANT SUPERVISORS}

Evalotte Mörelius, Associate Professor

Department of Social and Welfare Studies, Division of Nursing Science

Linköping University

Norrköping, Sweden

Annette Theodorsson, Professor

Department of Neurosurgery and Department of Clinical and Experimental Medicine Linköping University

Linköping, Sweden

\section{OPPONENT}

Mikael Norman, Professor

Karolinska University Hospital

Stockholm, Sweden

\section{FACULTY BOARD}

Jan Ernerudh, Professor

Professor in Clinical Immunology at the Department of Clinical and Experimental

Medicine, Faculty of Health Sciences

Linköping University

Consultant in Clinical Immunology and Neurology

Linköping University Hospital

Linköping, Sweden

\section{Margareta Kristenson, Professor}

Department of Medical and Health Sciences, Division of Community Medicine

Linköping University

Linköping, Sweden

Uwe Ewald, Professor emeritus

Department of Women's and Children's Health, International Maternal and Child Health Uppsala University

Uppsala, Sweden 


\section{ABSTRACT}

A functional stress-response system is essential for survival at birth, as well as for health and further development. Altered cortisol response and hypothalamic-pituitary-adrenal system function may have both short and long-term effects on health and development throughout life. Cortisol secretion follows a circadian rhythm in adults. Data in the literature concerning basal cortisol levels is scant, with divergent results regarding the timeframe for establishment of cortisol circadian rhythm in children. Nevertheless, cortisol is often studied in stress-related research concerning preterm infants, full-term infants, and infants at high psychosocial risk.

This thesis aimed to investigate at what age cortisol circadian rhythm develops in healthy full-term infants, preterm infants, and infants at high psychosocial risk and to identify whether such development is dependent on gestational or postnatal age. A secondary aim was to investigate whether either behavioral regularity or daily life trauma are associated with establishment of cortisol circadian rhythm. The last two interventional studies explored whether a) parental participation in the Hagadal daycare attachment program in one study and b) oral administration of glucose during nasopharyngeal suctioning in the other study influenced development of salivary cortisol circadian rhythm and/or cortisol levels. The effects, if any, of the Hagadal daycare attachment program on caregiver sensitivity to infants were also investigated.

The present thesis includes four original studies. Papers I, II, and III describes prospective, longitudinal studies extending over a year, including a survey of the cortisol levels and development of cortisol circadian rhythm in three infant groups. Paper III also included an intervention component addressing the possible effects of the Hagadal daycare attachment program. Paper IV describes a case-control study designed to generate paired baseline-response data concerning the effects of oral glucose administration during nasopharyngeal suctioning as an interventional procedure.

Cortisol circadian rhythm in salivary cortisol secretion was similarly established at one month postnatal age in full-term infants and at one month corrected age in preterm infants, 
reflecting a process dependent on gestational age. This rhythm persisted throughout the first year of life in all infants and consolidated over time in healthy full-term and preterm infants, but not in infants at high psychosocial risk, who displayed higher variability in cortisol levels. The infants in paper IV had not yet reached one month of corrected age and therefore had not yet developed cortisol circadian rhythm at the time of the investigation. No correlation was found between development of cortisol circadian rhythm and either behavioral regularity or reported traumatic life events. This thesis presents data on salivary cortisol levels among three different groups of infants during the first year of life. Cortisol circadian rhythm among infants in study III evolved in response to parental participation in the Hagadal daycare attachment program, which increased caregiver sensitivity to infants. Study IV found that nasopharyngeal suctioning was not a sufficiently stressful stimulus to increase salivary cortisol or impact pain score. Oral glucose administration had no effect on salivary cortisol levels.

This thesis concludes that cortisol circadian rhythm is already established in infants by one month of age, earlier than previous studies have shown, and further that this process is dependent on gestational age. The Hagadal daycare attachment program enhances parental sensitivity toward children, which helps to stabilize development of cortisol circadian rhythm. 


\section{SUMMARY IN SWEDISH}

\section{Populärvetenskaplig sammanfattning på svenska}

\section{Utveckling av dygnstytm hos nyfödda barn}

Ett fungerande stresshanterings system hos nyfödda barn är livsnödvändigt för såväl överlevnad vid födseln som för fortsatt hälsa och en normal utveckling. Om balansen i detta system störs kan det leda till en ogynnsam förändring i utsöndringen av kortisol som är ett livsnödvändigt hormon för att hantera stress. En störning av kortisolutsöndringen kan ha negativa hälsoeffekter även på lång sikt. Normaltsöndring av kortisol sker under hela dygnet med de högsta nivåerna tidigt på morgonen och de lägsta på kvällen. Denna så kallade dygnsrytm i utsöndring av kortisol ser man normalt hos vuxna och barn äldre än ett år. Hittills vet man inte exakt när under det första levnadsåret som barn utvecklar en dygnsrytm i kortisolutsöndring.

Denna avhandling syftar till att undersöka vid vilken ålder dygnsrytmen i salivkortisolutsöndringen utvecklas hos friska fullgångna barn, hos förtidigt födda barn och hos barn till psykosocialt belastade familjer. Dygnsrytmutvecklingen av kortisolutsöndring har även studerats i relation till vilken graviditetsvecka barnet föds i (gestationsålder) respektive barnets ålder efter födelsen (postnatal ålder). Sambandet mellan regelbundenheten i barnets vardagliga beteende (sömn och matvanor t.ex.) och utveckling av dygnsrytm i kortisolutsöndringen har också undersökts. Effekten av relationsstödjande behandling för att förbättra anknytning mellan förälder-barn hos psykosocialt belastade familjer har värderats. Totalt har 14168 saliv kortisolprover undersökts från 206 spädbarn och ligger till grund för avhandlingen.

Dygnsrytmen i salivkortisolutsöndringen hos fullgångna spädbarn etableras vid en månads ålder och hos de för tidigt födda barnen vid en månad korrigerad ålder (gestations vecka 40 + en månad). Dygnsrytmen blir mer uttalad med tiden under det första levnadsåret hos de friska fullgångna och de förtidigt födda barnen, men inte på samma sätt hos barn i psykosocialt belastade familjer. Barnen som föddes med hög psykosocial risk visade en större variation i kortisolnivåer. Hos barnen till psykosocialt belastade föräldrar, blev 
dygnsrytmen i kortisolutsöndringen mer uttalad under den relationsstödjande behandlingen. När dagverksamheten upphörde kvarstod dygnsrytmen men utvecklingen avstannade och dessa barn behöll en större variation i kortisolnivåerna. Likaså ökade dagverksamheten föräldrarnas känslighet för sitt spädbarns signaler. 


\section{LIST OF PAPERS}

This thesis is based on the following original papers, which are referred to throughout the text by their Roman numerals:

Paper I Ivars K, Nelson N, Theodorsson A, Theodorsson E, Ström JO, Mörelius E. Development of Salivary Cortisol Circadian Rhythm and Reference Ranges in Full-term Infants.

PLoS ONE 2015; DOI:10.1371/journal.pone.0129502

Paper II Ivars K, Nelson N, Theodorsson A, Theodorsson E, Ström JO, Mörelius E. Development of Salivary Cortisol Circadian Rhythm in Preterm Infants.

Submitted.

Paper III Ivars K, Nelson N, Gustafsson PA, Theodorsson E, Mörelius E.

Development of Salivary Cortisol Circadian Rhythm in Infants at High Psychosocial Risk in attachment program.

Submitted.

Paper IV Ivars K, Nelson N, Finnström O, Mörelius E.

Nasopharyngeal suctioning does not produce a salivary cortisol reaction in preterm infants. Acta Paediatrica 2012;101:1206-1210 


\section{ABBREVIATIONS}

$\begin{array}{ll}\text { ACTH } & \text { Adrenocorticotropic Hormone } \\ \text { AGA } & \text { Appropriate for Gestational Age } \\ \text { ANOVA } & \text { Analyze of Variance } \\ \text { AUC } & \text { Area under the Curve } \\ \text { BBQ } & \text { Baby and Behavior Questionnaire } \\ \text { CA } & \text { Corrected Age } \\ \text { CCR } & \text { Cortisol Circadian Rhythm } \\ \text { CPAP } & \text { Continuous Positive Airway Pressure } \\ \text { CRH } & \text { Corticotrophin-Releasing Hormone } \\ \text { CRIB } & \text { Clinical Risk Index for Babies } \\ \text { GA } & \text { Gestational Age } \\ \text { HPA } & \text { Hypothalamic-Pituitary-Adrenal } \\ \text { HR } & \text { Heart Rate } \\ \text { LITE } & \text { Life Incidence of Traumatic Events checklist } \\ \text { NICU } & \text { Neonatal Intensive Care Unit } \\ \text { NIDCAP } & \text { Newborn Individualized Developmental Care and Assessment } \\ & \text { Program } \\ \text { NPS } & \text { Nasopharyngeal Suctioning } \\ \text { PNA } & \text { Postnatal Age } \\ \text { SaO } 2 & \text { Oxygen Saturation } \\ \text { SGA } & \text { Small for Gestational Age } \\ \text { SES } & \text { Socioeconomic Status } \\ \text { SSP } & \text { Strange Situation Procedure } \\ \text { TCM } & \text { Topical Cortisone Medication } \\ \text { VAS } & \text { Visual Analogue Scale } \\ & \end{array}$




\section{CONTENTS}

ABSTRACT V

SUMMARY IN SWEDISH VII

Populärvetenskaplig sammanfattning på svenska $\quad$ VII

Utveckling av dygnsrytm hos nyfödda barn VII

LIST OF PAPERS IX

$\begin{array}{ll}\text { ABBREVIATIONS } & \text { XI }\end{array}$

$\begin{array}{ll}\text { CONTENTS XIII } & \text { XNS }\end{array}$

BACKGROUND 1

Developmental origins of adult disease 1

The preterm infant $\quad 2$

Perinatal brain development 3

Stress/Pain 3

Cortisol 4

Cortisol circadian rhythm $\quad 4$

Infants at high psychosocial risk $\quad 5$

High psychosocial risk - insecure attachment, cortisol levels and development of circadian rhythm $\quad 6$

Salivary cortisol $\quad 7$

Possible influencing factors on development of cortisol circadian rhythm $\quad 8$ $\begin{array}{ll}\text { Regularity } & 8\end{array}$

Trauma 9

Maternal Tobacco usage 9

$\begin{array}{lr}\text { Attachment } & 9\end{array}$

$\begin{array}{ll}\text { Interventions } & 10\end{array}$

HYPOTHESIS AND AIMS

Hypothesis $\quad 13$

General aims $\quad 14$

$\begin{array}{ll}\text { Specific aims } & 14\end{array}$

METHODS

Design $\quad 15$

Subjects $\quad 16$

Medical history: infants $\quad 16$ 
Infants from families at high psychosocial risk

The Hagadal daycare attachment program - Intervention I 17

Saliva sampling $\quad 18$

Salivary cortisol circadian rhythm 18

Salivary cortisol baseline - response in relation to intervention I 18

Salivary cortisol baseline - response in relation to intervention II 18

Saliva sampling method $\quad 19$

Salivary cortisol analysis using radioimmunoassay 19

Radioimmunoassay method 20

The baby and behavior questionnaire $\quad 21$

Life incidence of traumatic events checklist

Ainsworth's sensitivity scale $\quad 21$

Confounding factors $\quad 22$

Nasopharyngeal suctioning - Intervention II 23

Physiological monitoring in preterm infants $\quad 24$

$\begin{array}{ll}\text { Statistics } & 24\end{array}$

Cortisol Circadian Rhythm $\quad 24$

Area under the curve $\quad 25$

Cortisol circadian rhythm in relation to the Hagadal daycare attachment program 25

Gestational age vs postnatal age $\quad 26$

Salivary cortisol levels $\quad 26$

Individual Cortisol Circadian Rhythm 26

Regularity measured using the baby and behavior questionnaire 26

$\begin{array}{ll}\text { Life incidence of traumatic events checklist } & 27\end{array}$

Ainsworth $\quad 27$

Reactivity in cortisol Baseline - Response to oral glucose and nasopharyngeal $\begin{array}{ll}\text { suctioning } & 27\end{array}$

$\begin{array}{ll}\text { Ethical approval } & 28\end{array}$

RESULTS 29

Development of salivary cortisol circadian rhythm 30

Figure 1a. Healthy Full-term Infants Cortisol Circadian Rhythm 31

Figure 1b. Preterm Infants Cortisol Circadian Rhythm 31

Figure 1c. Infants at High Psychosocial Risk Cortisol Circadian Rhythm 31

Persistence and possible strengthening of salivary cortisol circadian rhythm during the first year of life: $\quad 32$

Figure 2a-c. Individual development of cortisol circadian rhythm 33

Cortisol circadian rhythm development among preterm and full-term infants was dependent on gestational age rather than postnatal age 34

Comments concerning possible confounding factors for development of cortisol circadian rhythm $\quad 34$

Topical cortisone medication $\quad 34$

Maternal smoking during pregnancy $\quad 35$ 
Data differences: social versus psychiatric reason for referral to Hagadal attachment

program

Psychological counseling during pregnancy 35

Salivary cortisol levels $\quad 35$

Table 1a. Salivary cortisol levels in full-term infants and differences in

evening/morning cortisol levels 36

Table 1b. Salivary cortisol levels in preterm infants and differences in

evening/morning cortisol levels 36

Table 1c. Salivary cortisol levels in infants at high psychosocial risk and differences in evening/morning cortisol levels 37

Table 1d. Salivary cortisol baseline levels in preterm infants and full-term infants in

morning and afternoon total 44 samples $\quad 37$

Development of regularity among infants during the first year of life, as measured by

the baby and behavior regularity item 38

Possible correlation between the baby and behavior questionnaire regularity and

development of cortisol circadian rhythm 38

Possible correlation between traumas as measured using the Life incidence of traumatic events checklist and development of cortisol circadian rhythm 39

Intervention I

Impact of Hagadal daycare attachment program 39

Intervention II $\quad 39$

Possible effects of nasopharyngeal suctioning and possible effects of $30 \%$ oral

glucose treatment 39

DISCUSSION $\quad 41$

Development of salivary cortisol circadian rhythm $\quad 41$

Development of cortisol circadian rhythm dependent on gestational age $\quad 42$

Cortisol circadian rhythm develops and becomes more pronounced with time 43

Possible correlation between behavioral regularity and cortisol circadian rhythm

Cortisol in children at high psychosocial risk 44

Impact of attachment program - Intervention I $\quad 45$

Impact of oral glucose during nasopharyngeal suctioning - Intervention II 46

Confounding factors affecting development of cortisol circadian rhythm 47

Life incidence of traumatic events $\quad 48$

CONCLUSIONS

ETHICAL CONSIDERATIONS

$\begin{array}{ll}\text { ERRATA } & 53\end{array}$

$\begin{array}{ll}\text { LIMITATIONS } & 55\end{array}$ 
ACKNOWLEDGEMENTS

REFERENCES

APPENDIX (PAPERS I - IV) 


\section{BACKGROUND}

\section{Developmental origins of adult disease}

The foundation of adult health and resilience is largely established at an early age, sometimes even before birth or in neonatal life. Scientific concerns regarding early infant life have considerably increased in recent years due to growing recognition and influence of the Barker hypothesis. The Barker hypothesis, which addresses the prenatal and early developmental origin of adult disease, suggests that health-related factors during the fetal and neonatal periods may be associated with an increased likelihood of and predisposal to illness in adult life [1]. Low birthweight has been linked to increased coronary heart disease morbidity and mortality in adults [2, 3]. A number of studies have reported that small for gestational age (SGA) children are at higher risk of developing coronary heart disease as adults [4], as well as for coronary heart disease mortality [5], impaired glucose tolerance/insulin resistance/type II diabetes [6-8], and hypertension [9].

However, several early life factors influence adult health; for instance, fetal development has been identified as a better indicator of disease than birth weight alone [10]. Moreover, researchers have identified preterm birth among infants who are appropriate for gestational age (AGA) as a major risk factor for several adult diseases, including arterial hypertension [11], type II diabetes [12, 13], cardiovascular disease [14], and stroke [15]. In recent decades, modern medicine has made enormous strides in neonatal care both technically and pharmacologically, while advances in nursing have made it possible to rescue seriously ill infants at earlier gestational ages (GA) $[16,17]$. Both genetic predisposition and nutritional (diet) factors have been considered independently and in tandem concerning later predisposal to coronary heart disease and type II diabetes. Epigenetic studies have highlighted the importance of developmental origins for a vast range of chronic diseases among adults [18]. Furthermore, epidemiology studies have examined environmental factors such as the effects of lifestyle on the development and onset of diseases like type II diabetes. Nevertheless, uncertainty still exists between correlation and causation; it is unknown whether rapid changes in the incidence of disease are due to genetic or environmental factors [19]. The maternal environment is known to affect fetal birthweight, for example through nutrition and smoking [20-22], but at the same time maternal nutrition 


\section{BACKGROUND}

and smoking are often associated with low socioeconomic status (SES). These three factors - maternal nutrition, smoking, and low SES - are all linked with low birthweight [10, 20, 23], a correlation further supported by a study concerning smoking [24], which shows that low SES and low birthweight are often found together with preterm birth [9, 25]. In addition, smoking and low SES are known risk factors for preterm birth [26, 27].

\section{The preterm infant}

In Sweden (2014) 7.2\% of infants are born preterm and 1\% are born before gestational week 30 [28]. The number of preterm births increases with psychosocial risk factors and with low SES, varying between populations of different countries as well as within countries. Preterm infants are a heterogeneous group with highly varied needs regarding level of neonatal care and medical treatment, depending on factors such as GA, pregnancyrelated circumstances and/or various complications. Proper development of the hypothalamic-pituitary-adrenal (HPA) axis and cortisol secretion are essential for lung maturation at birth, and cortisol levels increase in tandem with increasing GA [29-31]. Preterm infants benefit from administration of antenatal steroids to the mother prior to birth, which reduces neonatal mortality and severe neonatal morbidity in regard to conditions such as respiratory distress and intraventricular hemorrhage [32, 33]. In addition to the challenges posed by preterm birth, intensive care in itself can be quite stressful. Several infants may be under care in the same room, with the constant presence of noise from staff and medical equipment. In addition, stress may be increased by the frequency of repetitive handling (diaper changes, repositioning, weighing, personal hygiene) and invasive interventions (nasopharyngeal suctioning, blood sampling). Preterm infants in the neonatal intensive care unit (NICU) are subjected to between five and ten painful and stressful procedures daily, most of which are performed without analgesia, despite the ability of infants to perceive and feel pain [34]. Johnston and colleagues reported that preterm infants were subjected to a mean of six tissue-damaging and 14 non-tissuedamaging procedures in one week [35]. Compared with full-term infants, preterm infants are at greater risk of short-term consequences of stress (e.g., fluctuations in intracranial blood pressure with increased risk of intraventricular hemorrhage) [36, 37], as well as the long-term consequences [38]. Modern health care is also charged with the responsibility of 
focusing on long-term outcome and determining what supportive measures to undertake to ease the burden of severe illness and of the necessary invasive treatments carried out in the NICU.

\section{Perinatal brain development}

Brain development begins in the third week of gestation and continues throughout fetal life and childhood. Pain reactions as reflected by avoidance movements can be ascertained by the twentieth week of pregnancy in the human fetus [39]. The distinguishing characteristic between the human brain and animal brains is the extensive human cerebral cortex. The cerebral cortex begins to increase in size from the sixth month of pregnancy until the folding that gives rise to convolutions and furrows occurs [39]. In preterm infants organ systems are already functional, but usually somewhat immature. The brain is no exception and in very preterm infants it is completely smooth at birth, with fewer convolutions by gestational week 40 than found among healthy full-term infants born at GA week 37-42 [40], a difference associated with poorer cognitive outcome [41, 42]. Brain volume correlates with GA at birth and even among infants at low risk for neurodevelopmental deficits, prematurity impacts neurodevelopmental and cognitive outcome in children at 9 years of age [42]. However, prematurity is not the only factor that affects the developing brain. Several studies show that maternal separation and poor maternal care in animals have important effects on the developing hippocampus and amygdala, and also increase activation of the HPA axis [43-45]. Among human infants who are neglected in infancy or receive inappropriate care amygdala volumes are enlarged and the HPA axis is activated $[46,47]$.

\section{Stress/Pain}

The definition of stress is a matter of debate. McEwen defines stress as a real or interpreted threat to the physiological or psychological integrity of an individual that results in physiological and/or behavioral responses. Stress in biomedicine often refers to situations in which adrenal glucocorticoids and catecholamines are elevated in response to a particular experience [48]. The first obvious and distinct stressful situation in human life is birth, which is stressful for all infants, including what has been described earlier for preterm 


\section{BACKGROUND}

infants, [49]. Three specific groups of clinically vulnerable newborns are preterm infants, non-healthy infants, and infants born in families at high psychosocial risk. These three risk factors often coexist in a stressful environment. Prolonged stress may result in longstanding elevated cortisol concentrations, which can have a deleterious effect on the individual regarding impaired memory, learning disabilities, and insulin resistance [50, 51]. Pain and stress are not easily distinguished from one another in infants. Therefore, when observing infants we often find the same reaction pattern to what we assume would be a stressful and/or painful situation. Pain is defined by the International Association for the Study of Pain as "An unpleasant sensory and emotional experience associated with actual or potential tissue damage, or described in terms of such damage."

\section{Cortisol}

Cortisol is classified as one of the main stress hormones and is essential to prepare the body for action. Cortisol is used as a major indicator of stress among adults, children and infants [52-54]. The fetal HPA system responsible for cortisol release is functional from the beginning of the second trimester [55]. Stress or pain activate the sympaticoadrenomedullary system. Corticotrophin-Releasing Hormone $(\mathrm{CRH})$ is produced locally in the hypothalamus and secretion increases rapidly with stress. $\mathrm{CRH}$ induces secretion of Adrenocorticotropic Hormone (ACTH) from the pituitary gland, which stimulates cortisol release. Cortisol is the main glucocorticoid hormone and is secreted by the adrenal cortex into the bloodstream where it stimulates an increase in heart rate (HR) and respiratory rate, thereby transporting more blood-carrying oxygen and energy to end organs such as muscle and brain. The body prepares for survival and a "fight or flight" response. Peripheral blood vessels constrict to defend against blood loss, while the brain releases endorphins for pain relief $[48,56]$. Activation of the HPA axis results in secretion of glucocorticoids. Cortisol secretion generally peaks 20-30 minutes after a stressor event such as pain or intervention $[57,58]$.

\section{Cortisol circadian rhythm}

Cortisol secretion is pulsatile and known to display a circadian rhythm in adults and older children. Cortisol levels peak in the morning and subsequently drop to a nadir in the 
evening $[59,60]$. Infants are thought to develop this adult-like cortisol circadian rhythm (CCR) during the first year of life, but exactly when has not yet been established. This information is necessary if salivary cortisol is to be used for diagnostic and research purposes. Seven prior studies of full-term infants have explored development of CCR in salivary cortisol secretion, but have reached different conclusions regarding when CCR is established, varying from two weeks to more than nine months of age. However they all agree that CCR develops during the first year of life in full-term infants [61-67]. These divergent results may have a variety of possible explanations: lack of consensus regarding the definition of CCR, different sampling techniques, low sampling numbers, and a small number of participants (often fewer than 20, never more than 75).

Seven earlier studies have explored the development of CCR in preterm infants [68-74], three of which investigated cortisol in saliva [69-71]. To date, there has been no general consensus regarding when CCR is established. Few studies have investigated whether CCR development is dependent on GA or postnatal age (PNA). One study investigated CCR dependency on age and found a significant inverse relationship with higher cortisol levels at lower GA [73].

\section{Infants at high psychosocial risk}

Infants at high psychosocial risk are highly vulnerable. Such infants are identified as living in families that fulfill at least one of the following criteria: caregiver with previous alcohol and/or drug abuse problem, caregiver with psychiatric problems/disease (e.g. anxiety disorders, schizophrenia, depression), specific social circumstances of relevance to parenthood (e.g. unknown father, mother pregnant before age 17, permanent disability, prison record, prior record of children in foster care, emotional and/or physical problems caring for the baby), infant symptoms (eating disturbances; sleeping problems; excessive crying) [75]. Infants at high psychosocial risk are often overrepresented among preterm infants, since low SES as well as teenage pregnancy are risk factors for preterm childbirth $[27,28]$. Ten-year old children whose mothers displayed symptoms of depression since childbirth, had increased levels of glucocorticoids and an increase in amygdala volume [76]. Moreover, a significant positive correlation was observed between mean depressive scores 
of mothers and amygdala volume in their children [76]. Human studies were preceded by studies on rat pup, which found that separation from the mother activated the HPA axis, thereby increasing circulating levels of ACTH and glucocorticoids [77]. When they reached adulthood, rat pups subjected to maternal separation exhibited increased anxiety-like behavior, impaired cognitive capabilities, and dysregulation of the HPA axis [78]. Several animal studies associated maternal separation and poor maternal care in the neonatal period with structural changes in brain regions linked to cognition and mood regulation, including the hippocampus and the amygdala [79-82]. In human research, similar studies were initially performed on adults who reported parental loss or poor quality of maternal care during early childhood. These adults showed higher basal levels of cortisol [83, 84], increased cortisol reactivity to stressors [85] and, in some cases, reduced hippocampal volume [86]. Childhood abuse and maltreatment was significantly associated with reduced hippocampal volume in adults [82, 87-89], but not in children [90-92]. Orphanage rearing was not associated with changes in hippocampal volumes in children [46, 47] although enlarged amygdala volumes were [46, 47].

Maternal depression often interferes with sensitive and supportive care of infants and young children. There is increasing evidence that children of mothers with depressive symptomatology, especially those with clinical depression during their child's early years, demonstrate increased activity in the HPA axis during childhood and adolescence [76, 9396] and are also found to have significantly larger amygdala volumes [76].

\section{High psychosocial risk - insecure attachment, cortisol levels and development of circadian rhythm}

Toddlers with insecure attachment have previously been shown to react with increased cortisol levels in response to novelty situations and Ainsworth's strange situation procedure (SSP) [97-99]. Spangler et al. 1993 found that the insecurely attached infant, unlike the securely attached infant, showed increased cortisol response to SSP, which was interpreted as a lack of appropriate coping strategies [99]. Maternal depression during a child's first two years of life may predict elevated baseline salivary cortisol in children [96]. High maternal stress during pregnancy predicts high infant cortisol levels (in infants $>9$ months 
of age) with high total area under the curve (AUC). High maternal cortisol levels during pregnancy also affect in utero cortisol levels [100]. Infants aged 12-20 months from lowincome families display higher AUC levels than infants from high-income families, suggesting delayed CCR in the former, which when combined with postnatal parental stress results in further elevation of AUC levels [101]. Children (one to six years old), born to a normal population of healthy mothers who self-reported maternal stress, anxiety, and psychological stress during their infants' first years of life, show altered cortisol AUC and CCR development [102], as do older children (six to ten years old) of low SES whose basal cortisol levels are increased [93]. Both adults and adolescents with altered CCR (higher basal levels and flatter slope) have retrospectively reported early childhood adversity [84, 103].

Studies of infants and children beginning at age 9 months indicate that children at high psychosocial risk demonstrate higher variability in cortisol levels and higher total AUC cortisol, while CCR development is rarely investigated. It is well known that long-term elevation of cortisol levels is associated with various health problems including diabetes, hypertension, depression, behavioral problems, and cognitive impairment (memory, learning and concentration deficiencies) [51, 104-111]. To adequately aid these fragile but otherwise normal infants with both individualized care for the child and support to the caregiver, further investigations and advances are critical.

\section{Salivary cortisol}

Cortisol can be measured in different body fluids (plasma, serum, urine, and saliva [112]. For our projects we chose salivary cortisol because of its reliability and other advantages, especially because collection of saliva does not cause stress or pain for the infant $[113,114]$. Since the method is neither stressful nor painful for the infant, sampling by itself will not raise the cortisol level. Furthermore, sampling is easy to perform and does not interfere with daily activities or the environment [115]. Cortisol sampling can easily be performed at home, and is stable at room temperature for at least one week [52, 116]. Cortisol samples are stable in the refrigerator for at least three months and in the freezer $\left(-20^{\circ} \mathrm{C}\right)$ for at least for nine months [116-118]. Furthermore salivary cortisol, which correlates well with plasma 
cortisol, represents the unbound, physiologically active, free fraction of cortisol, while plasma cortisol includes both the free and receptor-bound fractions of cortisol [59].

Altered salivary cortisol levels have been associated with several psychological and physiological conditions. Preterm infants have higher cortisol levels than healthy full-term infants [119] and also show diverse cortisol responses to various interventions such as skinto-skin care with the mother, as well as to diaper changes [119, 120]. A regular diaper change increases cortisol levels in full-term infants born to mothers in psychosocially stressed families, but it has also been shown that this reaction may be reduced by providing support to the mothers in parenting and attachment to the child through a specific environmental therapeutic program [121].

Cortisol increases in response to painful or stressful clinical procedures such as examinations for retinopathy of prematurity (ROP) [122] and blood sampling [123, 124]. Painful examinations and procedures elevate cortisol levels, while experiences that are presumably pleasant such as prone positioning and music have been shown to lower cortisol levels $[125,126]$.

Reference intervals for salivary cortisol levels in infants during the first year of life have not previously been published. Salivary cortisol reference intervals for healthy, full-term infants up to one year of age are likely to be of value both for future research and in clinical practice to evaluate cortisol levels as expressions of stress or disease.

\section{Possible influencing factors on development of cortisol circadian rhythm}

\section{Regularity}

Previous studies have investigated factors that may influence development of CCR in infants. Price et al. (1983) found a weak correlation between evolution of CCR and regularity in sleep (age when infants start to sleep more than six consecutive hours) in full- 
term infants. Antonini et al. investigated "regularity" in preterm infants by studying sleep time, which increased at 8 weeks PNA during the same period that infants develop CCR, but no significant correlation was found.

\section{Trauma}

Different life situations, including trauma, influence the HPA axis, and thereby cortisol secretion and circadian rhythm. An earlier study on adolescents demonstrated that trauma affects the HPA axis by raising morning cortisol levels, while evening levels remained unchanged [127]. In contrast, multiple traumas lower basal cortisol and flatten the CCR curve in adults [128].

\section{Maternal Tobacco usage}

Smoking during pregnancy increases the risk of preterm birth, intrauterine growth retardation, placental abruption, and intrauterine stillbirth [24]. Nicotine passes to the fetus, and fetal concentrations are reported to be 15 percent higher than maternal concentrations when using snuff [129]. In Sweden, smoking during pregnancy has declined from $31.4 \%$ in 1983 to $5.5 \%$ in 2014 [28]. In 2014, 1.3\% of pregnant women used snuff [28]. There may possibly be a connection between nicotine dose and fetal outcome [25]. Nicotine does not just affect serum levels of stress hormone levels, but also other hormones including vasopressin, endorphins, growth hormone, and ACTH [129, 130]. McDonald et al. in 2006 concluded that infants exposed to tobacco in utero had elevated ACTH levels [131], while Saridjan et al. noted effects on cortisol variability among children 14 months of age whose mothers smoked during pregnancy [101]. The majority of experimental animal studies report that nicotine reduces blood flow in the uterine arteries and thus blood flow to the placenta [129]. Altered blood flow in both the uterine arteries and the umbilical artery has been demonstrated in humans after exposure to nicotine [132].

\section{Attachment}

During the first year of life infant emotional expressions play an important role for infant development, interaction, and attachment. Emotional expressions are evoked by various situations, including infant distress or anxiety, evolving from early negative expressions 


\section{BACKGROUND}

(especially crying) to single words spoken by the end of the first year [133]. Infant emotional expression combined with caregiver response as reflected by the ability to perceive and adequately interpret infant signals (caregiver sensitivity), form the foundation of infantparent attachment. This attachment is crucial for development of social and emotional skills in the child [97, 133-135]. According to Ainsworth and colleagues [136], an infant will form an attachment around the middle of the first year of life if reared in an environment where at least one adult is consistently psychologically accessible. Caregiver sensitivity to infant signals can be evaluated and measured using the Ainsworth sensitivity scale [97, 136]. The Ainsworth SSP is used to classify development of infant attachment to caregivers [97, 137]. Infants from families at high psychosocial risk are more likely to become insecurely attached and to develop poor mental health than infants from low-risk families [75, 138142]. The greater the number of psychosocial risk factors such as isolation, teenage parents, and poverty, the greater the risk for psychiatric problems during childhood [143, 144]. Psychological demands may evoke stress responses in infants $[98,99]$. Whereas duration of various problems within families is important, so too are protective factors [144]. Linköping has a well-designed daycare program aimed at improving attachment in such high-risk families $[75,121]$. A secure pattern of attachment is associated with high maternal sensitivity during the first year of life $[97,134,145]$.

\section{Interventions}

To improve the situation for neonates in the NICU, stress-reducing interventions have been implemented [146-150] and evaluated [71, 120, 122]. Salivary cortisol levels early in the life of preterm infants have been studied in response to various painful treatmentrelated hospital interventions such as heel lance [124, 151-157], eye screening examination [122], and various other painful procedures [151]. The aim was to alleviate the resulting pain through various experimental interventions: oral sucrose [153], water vs. sucrose during one week [151], incubator care vs skin-to-skin care [154], formula odor vs. breast milk odor [155], standard care vs. co-bedding [156, 157], standard care vs. newborn individualized developmental care and assessment program (NIDCAP) [122]. When response cortisol levels were compared with baseline, one study found a significant decrease [157], while another found an increase [122]. Earlier studies have found that 
cortisol reactivity is most pronounced in response to painful interventions $[122,124]$. While preterm infants may be capable of producing sufficient cortisol to maintain homeostasis under non-stressful conditions, their developmental immaturity may result in an insufficient or completely absent response to a stressor [158, 159]. Preterm infants have exhibited altered HPA axis function at young age (three, eight, and 18 months, as well as at seven years) $[160,161]$. Elevated salivary cortisol levels in preterm infants have previously been found to correlate with the degree of pain to which the infants were exposed during the neonatal period [162-164].

The most common daily treatment interventions in NICUs include nasopharyngeal suctioning (NPS), endotracheal suctioning, blood sampling, and intravenous cannula insertion $[34,35,165,166]$. NPS is considered both stressful and painful, and is associated with the physiological responses that accompany other painful interventions $[167,168]$. Oral glucose has been used to alleviate painful interventions in newborns for many years [169-171]. Boyer et al. investigated cortisol reactivity in relation to administration of a sweet-tasting solution as analgesia, but found no difference 30 minutes after painful stimulation between preterm infants who received sucrose and those who did not [151]. Mörelius et al. found a significant decrease in cortisol levels 30 minutes after immunization injections when infants were given glucose and a pacifier [172]. 
BACKGROUND 


\section{HYPOTHESIS AND AIMS}

\section{Hypothesis}

The hypothesis underlying this thesis was that infants develop a circadian rhythm in cortisol secretion sometime during their first year of life. The specific hypothesis of the individual studies were as follows:

I. That healthy full-term infants develop a cortisol circadian rhythm during the first year of life and that the development correlates with development of behavior regularity.

II. That preterm infants develop a cortisol circadian rhythm during the first year of life and that the development is dependent on age, postnatal age and/or gestational age. That the development of cortisol circadian rhythm correlates with development of behavior regularity and that the development is delayed by certain illness factors.

III. That the development of cortisol circadian rhythm in infants at high psychosocial risk is delayed compared to the development of cortisol circadian rhythm in healthy full-term infants. That the Hagadal attachment program improves the development of cortisol circadian rhythm in infants at high psychosocial risk. That the development of cortisol circadian rhythm correlates with development of behavior regularity.

IV. That oral glucose ameliorates infants stress and/or pain response to nasopharyngeal suctioning in continuous positive airway pressure treated preterm infants. 


\section{General aims}

The principal aim of this thesis was to investigate development of salivary cortisol levels and circadian rhythm during the first year of life in three groups of infants: healthy fullterm infants, preterm infants, and infants at high psychosocial risk (papers I, II, and III). A secondary aim was to investigate possible factors that influence cortisol levels and development of cortisol circadian rhythm.

\section{Specific aims}

- To establish the age at which cortisol circadian rhythm is fully developed among infants in their first year of life (papers I, II, and III).

- To ascertain whether cortisol circadian rhythm development is dependent on gestational age or postnatal age (paper II).

- To track salivary cortisol levels during the first year of life (papers I, II, and III).

- To investigate possible correlations between cortisol circadian rhythm development and behavioral regularity (papers I, II, and III).

- To explore whether parental participation in a six-week daycare program intended to improve attachment for families at high psychosocial risk has an effect on cortisol circadian rhythm development.

- To investigate whether nasopharyngeal suctioning is a stress factor in continuous positive airway pressure -treated preterm infants or healthy full-term control infants.

- To investigate whether oral administration of $30 \%$ glucose may have an effect on a possible stress response to nasopharyngeal suctioning among preterm infants. 


\section{METHODS}

\section{Design}

Papers I-III were prospective longitudinal studies designed to determine the development of CCR in three different groups of infants during the first year of life. Samples were collected in the morning when cortisol levels reach their peak and in the evening when they fall to a nadir [115]. The protocols were set up to accommodate 130 full-term infants in study I, 51 preterm infants in study II, and 25 infants at high psychosocial risk in study III. Saliva samples were collected three times daily on two consecutive days. Sampling for fullterm infants (paper I), GA weeks 37 - 42, began in month 0, while sampling for preterm infants (paper II) was synchronized to the exact day on which each infant turned GA 28 or 32 weeks based on GA at birth, as well as on the infant's medical condition. Sampling for infants at high psychosocial risk (paper III) was based on age at inclusion in the Hagadal daycare attachment program. Sampling continued until full-term infants turned twelve months PNA and preterm infants turned twelve months corrected age (CA) [173].

Additionally paper III had an integrated baseline-response study design were the development of CCR and caregivers sensitivity was investigated in relation to an intervention, the six weeks long Hagadal daycare attachment program [75, 121]. The baseline-response measurements were adjusted to the treatment period of six weeks [75, 121]. The baseline is defined as the state prior to intervention, CCR and Ainsworth sensitivity rate at inclusion to the Hagadal daycare attachment program. "Response" refers to the possible increased stability in CCR as well as possible increased caregiver's sensitivity towards their infant, induced by the intervention, the Hagadal daycare attachment program.

Paper IV used a baseline-response cross-over design in which baseline is defined as the state prior to intervention, which in this study was NPS. "Response" refers to the possible stress or pain induced by the intervention and is expected to occur about 20-40 minutes after the intervention, as indicated by a rise in cortisol levels [115]. The intervention was performed twice and subjects acted as their own controls concerning possible influences from CCR and alleviation from oral glucose. 


\section{Subjects}

The studies were conducted in Sweden at Linköping University Hospital and at Ryhov Hospital in Jönköping; 130 healthy full-term infants (paper I) were recruited from the maternity wards and 51 preterm infants (paper II) were recruited from the NICUs, in equal numbers from each hospital. In addition, 25 infants from families at high psychosocial risk (paper III) were recruited from Hagadal daycare center in Linköping, which is run by the Department of Child and Adolescent Psychiatry at Linköping University Hospital. In paper IV 22 infants were recruited, eleven preterm infants from the NICU and eleven full-term infants from the maternity ward at Linköping University Hospital.

\section{Medical history: infants}

The infants studied in papers I, II, and IV were required to meet the inclusion criterion of birth to a healthy mother. Although all infants studied in paper I were healthy at birth, 19 of 130 were treated at some point with topical cortisone medication (TCM), on average three per month between the ages of three and twelve months. In the preterm study group (paper II), all mothers except one received antenatal steroids. During the first year of life from one month CA (paper II), 15 infants occasionally used TCM (ointment or inhalation), on average five infants per month. Among infants at high psychosocial risk (paper III), the newborn period was uneventful except for a transient low Apgar and respiratory adaptation in three infants. One included infant in paper III was treated with TCM (ointment) but only in one month, month twelve. The infant's cortisol levels for month twelve was presented separately and not included in any analyses. The infants in the intervention group from study IV were selected on the basis of prematurity (GA $<37$ weeks), need for treatment with continuous positive airway pressure (CPAP), and need for intermittent NPS. However, infants with severe neonatal complications or with mothers having endocrine disease were excluded since all these mothers were treated with prenatal corticosteroids. Neither the healthy full-term infants nor the preterm infants in study IV were treated with postnatal corticosteroids or other medicines. 


\section{Infants from families at high psychosocial risk}

The Department of Child and Adolescent Psychiatry in Linköping identifies high psychosocial risk families after they have been referred to the clinic, (for details see paper IV) and the families are offered a place in the Hagadal daycare attachment program. High psychosocial risk families fulfill at least one of the following criteria:

1. Caregiver with previous alcohol and/or drug abuse problem.

2. Caregiver with psychiatric problems/disease (e.g. anxiety disorders, schizophrenia, depression).

3. Family with specific social circumstances of relevance to parenthood (e.g. unknown father, mother pregnant before age 17, permanent disability, prison record, prior record of children in foster care, emotional and/or physical problems caring for the baby).

4. Infant symptoms (eating disturbances; sleeping problems; excessive crying).

\section{The Hagadal daycare attachment program - Intervention I}

The Hagadal daycare attachment program comprises an intensive three-day a week, sixweek daycare treatment program (paper III). Either the mother, the father or both caregivers together are enrolled with the infant for individualized support via a milieutherapeutic approach. Psychotherapy is also offered to caregivers (individual, family, or group). The focus is on enhancing caregiver sensitivity to communication signals from the child, thereby improving attachment [174]. The program is voluntary and free of charge. The staff includes one child psychiatrist, one psychologist, two social workers, and four family counselors. Usually mothers are referred to the clinic, but in some cases the whole family is referred from antenatal healthcare clinics or emergently from pediatric clinics, maternity clinics, or psychiatric clinics, depending on the nature of the reason for referral. The program was used as intervention in paper III. 


\section{Saliva sampling}

\section{Salivary cortisol circadian rhythm}

Parents performed saliva sampling after being instructed by healthcare personnel (papers I-III), or healthcare personnel performed the sampling (paper IV). Sampling was carried out at home (paper I), initially in the NICU until discharge and thereafter at home (paper II), at the daycare center and thereafter at home (paper III), or exclusively in the hospital (paper IV). No sampling was undertaken until infants were older than 48 hours to avoid interference from elevated postpartum cortisol levels [175, 176]. Once CCR becomes established the greatest differences in cortisol levels are found between early morning and late evening [59]; therefore sampling took place at 07:30 in the morning and 19:30 in the evening for in papers I, II, and III. To generate reference data, additional sampling was carried out between morning and evening at 10:00. Samples taken within the intervals 07:30-09:30, 10:00-12:00, and 19:30-21:30 were considered acceptable, whereas samples outside these limits were excluded. Sampling was conducted on two consecutive days beginning on the same date each month and synchronized with the infant's birthday, from the time of inclusion in studies I, II, and III until one year of age (GA week 40 plus twelve months).

\section{Salivary cortisol baseline - response in relation to intervention I}

In study III, in relation to the intervention (the Hagadal daycare attachment program), initial sampling was carried out during the infants' first week in the Hagadal daycare attachment program resembling baseline values and the second sampling resembling response values was carried out during week six, the last week of the program. Thereafter the samplings were monthly, synchronized with the infant's birthday and intended for investigation of CCR development in infants at high psychosocial risk.

\section{Salivary cortisol baseline - response in relation to intervention II}

In study IV, sampling was conducted twice daily (morning and afternoon), two samplings at each intervention - initial baseline samples before and response samples 30 minutes after intervention. Infants served as their own controls. All samples were to be collected no sooner than 30 minutes after intake of liquid food, 60 minutes after intake of solid food, 
or one hour after the infant slept, cried, or traveled by car. Saliva samples collected outside the hospital were stored in the refrigerator until parents mailed them (within one week) to the University Hospital in Linköping (salivary cortisol levels in samples have proven to be stable at room temperature for at least two weeks prior to analysis $[117,118])$.

\section{Saliva sampling method}

The same method was used to collect saliva samples from all infants for the studies in papers I-IV using two cotton swabs with plastic (Johnson's ${ }^{\circledR}$, Johnson and Johnson) shafts held together at one end by surgical tape (MicroporeTM, 3M, Sollentuna, Sweden) equipped with a protruding thread underneath the tape that allows the swabs to be suspended once they are placed in the test tube. To collect saliva the cotton swabs were gently moved around in the infants' mouths and removed when fully saturated with saliva, after which they were immediately placed in a tube (polypropylene tube Sarstedt ${ }^{\circledR}$, Landskrona, Sweden), and suspended by the sewing thread after which the cap was tightly screwed on. The tubes were all centrifuged in the hospital laboratory to separate the saliva from the cotton swabs; the latter were then removed and the tubes tightly capped once again. The samples were stored in the freezer, initially at $-22^{\circ} \mathrm{C}$ and subsequently at $-70^{\circ} \mathrm{C}$.

\section{Salivary cortisol analysis using radioimmunoassay}

A RIA to analyze salivary cortisol was developed, evaluated, and modified at the University of Linköping $[177,178]$. RIA is a reliable method that has been well-tested by our team and other research groups. In 2001 Nelson et al. published a modification of the commercially available methodology from Orion Diagnostica (Turku, Finland) [177], which was subsequently further refined to test smaller amounts of saliva $(10 \mu \mathrm{l})$ [113]. This method for collecting and preparing samples for analysis is well described in earlier articles $[113,114]$. Samples were run in duplicate. All samples for the study presented in paper IV were assayed in the same run, but because of the numerous samples generated for the studies in papers I-III, it was impossible to analyze all samples from each individual in the same run. 


\section{Radioimmunoassay method}

The modified RIA method requires just $10 \mu \mathrm{L}$ of saliva for a single cortisol detection analysis (paper IV). Cortisol antiserum (Orion Diagnostica, Turku, Finland) and radioligand [125 I]-cortisol (Origon Diagnostica, Turku, Finland) were both diluted in RIA buffer $(0.1 \mathrm{~mol} / \mathrm{L}$ phosphate buffer containing $0.02 \%$ bovine serum albumin and $0.01 \%$ triton $\mathrm{X}-100, \mathrm{pH}$ of 7.4 ) at a ratio of 1:40 respectively until $100 \mu \mathrm{L}$ registered $3000 \mathrm{CPM}$. To generate the standard curve, a cortisol control containing $150 \mathrm{nmol} / \mathrm{L}$ was serially diluted to a final dilution of $0.07 \mathrm{nmol} / \mathrm{L}$ using the same RIA buffer. Plain polystyrene tubes were initially labelled in duplicate: T (total cortisol), NSB (non-specific binding), and 0 -reference (only RIA buffer). Thereafter the twelve diluted calibrators containing the concentrations $0.07,0.14,0.29,0.59,1.17,2.34,4.69,9.38,18.75,37.5,75$ and 150 were run to create the standard curve. Finally the saliva samples and intraassay variation samples were run along with the two 0 -references.

1. Cortisol antiserum $(100 \mu \mathrm{L})$ was added to all tubes except the Ts and NSBs. RIA buffer was added to the NSB tubes $(110 \mu \mathrm{L})$ and to the 0 -reference tubes $(10 \mu \mathrm{L})$. Saliva samples and calibrators were added to their respective tubes in volumes of $10 \mu \mathrm{L}$ each.

2. All tubes were incubated for 48 hours at $+4^{\circ} \mathrm{C}$.

3. $100 \mu \mathrm{L}$ tracer (3000 CPM) was added to each tube.

4. A second incubation period followed at $+4^{\circ} \mathrm{C}$ for 24 hours.

5. A specific anti-rabbit antibody $(50 \mu \mathrm{L}$ solid phase second antibody coated cellulose suspension (SAC-CEL), Boldon, England) was added to all tubes except the Ts and allowed to incubate at room temperature for 30 minutes. One $\mathrm{mL}$ of distilled water was added to all tubes except the Ts. The samples were centrifuged at $3000 \mathrm{G}$ and $+4^{\circ} \mathrm{C}$ for 15 minutes before decantation.

6. The assay was analyzed in a Wallac (Turku, Finland) gamma counter 1277.

The intraassay variation of coefficient was $12 \%$ and $6 \%$ for 2.0 and $10.0 \mathrm{nmol} / \mathrm{L}$, respectively. The interassay coefficient of variation was $10.0 \%$ and $5.2 \%$ for 5.0 and 12.5 $\mathrm{nmol} / \mathrm{L}$, respectively. The detection limit was $0.15 \mathrm{nmol} / \mathrm{L}$. 


\section{The baby and behavior questionnaire}

The baby and behavior questionnaire (BBQ), validated 1985 in a Swedish sample by Hagekull et al., measures six parameters-Intensity/Activity, Regularity, Approach/Withdrawal, Sensory Sensitivity, Attentiveness, and Manageability-based on a total of 31 items (papers I-III) [179]. The six parameters are usually considered separately [179]. We studied Regularity by assessed each of six items based on a scale of increasing regularity from 1 to 5. The six items comprised: "Going to sleep at the same time," "Waking up at the same time," "Hungry at the same time," "Eating the same amount of food every day," "Taking a nap at the same time every day," and "Having a regular bowel movement schedule." Parents were asked to fill out the Swedish version of the BBQ in months one, six, and twelve in papers I-II and in months two to twelve in paper III.

\section{Life incidence of traumatic events checklist}

Life incidence of traumatic events (LITE) checklist is a validated questionnaire designed to detect trauma [180]. The Swedish version has been used in earlier studies [181]. The LITE checklist consists of 15 items with fixed answers about lifetime occurrence of traumatic life events, such as "a family member was hospitalized” (parent, sibling, grandparent, cousin, aunt or uncle), "parents separated" and "infant hurt or threatened". Parents were asked to fill out a Swedish translation of LITE (designed for infants) at birth (month zero), and at months one, six, and twelve.

\section{Ainsworth's sensitivity scale}

Caregiver sensitivity toward their infants was rated by the staff at Hagadal using one of the scales from the Baltimore Study by Mary Ainsworth (paper III) [97, 136]. Ainsworth's sensitivity scale is a nine-point bidimensional scale with five anchor points: $1=$ highly insensitive, 3 = insensitive, $5=$ inconsistently sensitive, $7=$ sensitive, and $9=$ highly sensitive [136]. Seven or above is recognized as well-functioning interaction. The parent's sensitivity was rated by the staff members in the beginning and in the end of treatment, based on observations made during the first and last week respectively. The staff members are well acquainted with Ainsworth's sensitivity scale, which has been in routine use for 
several years [121]. A highly sensitive mother (9 points) is exquisitely attuned to her baby's signals, and responds to them promptly and appropriately. She "reads" her baby's signals and communication skillfully. A sensitive mother (7 points) also responds to her baby's signals promptly and appropriately, but with less sensitivity and consistency than the highly sensitive mother. An inconsistently sensitive mother (5 points) can be quite sensitive on occasion but there are periods when she is insensitive to her baby's signals. However, she is more frequently sensitive than insensitive. An insensitive mother ( 3 points) frequently fails to respond to her baby's communication appropriately and/or promptly. Her insensitivity seems linked to inability to see things from the baby's point of view. A highly insensitive (1 point) mother's interventions and initiations of interaction are prompted and shaped largely by signals within herself. The highly insensitive mother seems geared almost exclusively to her own wishes, moods, and activities [136]. Seven or above is usually recognized as a well-functioning interaction. The Ainsworth scale has been used previously in several studies of caregiver sensitivity to infant signals [121, 182-184].

\section{Confounding factors}

TCM was not tested as a confounding factor in paper I. However, TCM was considered to be a possible confounding factor in paper II. To achieve uniformity in the statistics between papers I and II the data relating to TCM as a possible confounding factor in paper I of healthy full-term infants were included in the statistical analysis as controls for TCM as possible confounding factor on preterm infants in paper II. In paper III TCM was only used by one infant during one month and therefore no data are available for statistical analysis. TCM was not used by any infants included in paper IV.

Possible confounding factors for normal development of CCR in preterm infants (paper II) were monitored, including CRIB (clinical risk index for babies) score [185]. CRIB is a validated neonatal scoring system [186] that measures birth weight, GA, minimum and maximum fraction of inspired oxygen, and maximum base excess during the first $12 \mathrm{~h}$, as well as presence of congenital malformations. Other possible confounding factors monitored individually each month included: cortisone medication in NICU, severe disease (defined as: infants with respiratory distress syndrome, bronchopulmonary dysplasia, 
patent ductus arteriosus, and/or need for surfactant treatment), days at home vs days in NICU, and AGA or small for SGA at birth. No potential caregiver-related confounding factors were addressed in papers I or II, while paper III addressed three possible confounding factors relating to cortisol levels and development of CCR that were monitored and analyzed including: reason why families attended Hagadal (social/psychiatric/substance abuse/other), whether mothers received prenatal counseling (yes/no) and smoking status of the mother (yes/no).

\section{Nasopharyngeal suctioning - Intervention II}

NPS was performed by clearing mucus from the mouth and throat for a period of less than one minute, using a sterile Mülly suction catheter $\mathrm{CH} 06$ at a pressure of -0.2 bar (paper IV). NPS was carried out in two different settings, one for each population, preterm infants and full-term control infants. Both populations were investigated in the morning and in the afternoon serving as their own controls for possible diurnal influences.

The NPS procedure in the eleven preterm infants' were performed in the NICU by a single registered nurse who repeatedly performed the same study sequence in the morning and in the afternoon, while the preterm infant was placed in the incubator or hospital bed. Each infant was investigated twice and prior the intervention randomized to receive oral glucose prior the intervention in the morning or in the afternoon. The saliva samples were collected initial in morning for baseline, thereafter glucose for half of infants and nothing for the other half in the morning, suction mouth and throat, collect second saliva sample 30 minutes after NPS and the procedure was repeated in the afternoon but infants receiving glucose were reversed.

The NPS procedure in the eleven full-term infants' were performed on a nursery table in the maternity ward. A single registered nurse repeatedly performed the same study sequence: collect saliva for baseline, place infant on nursery table, suction mouth and throat, return infant to parent, collect second saliva sample 30 minutes after NPS. The procedure was repeated in the afternoon, no oral glucose was given for the full-term infants. 


\section{Physiological monitoring in preterm infants}

The visual analogue scale (VAS) [187], which ranges from 0 (no pain at all) to 10 (worst pain imaginable), was used to assess pain during NPS in the preterm infant group in paper IV, but not in full-term infants serving as controls. A stopwatch was used to measure recovery time after NPS, where recovery was deemed to have taken place once the infant returned to baseline according to a validated structured observation program: the NIDCAP observation sheet [146] (preterm infant population paper IV). A NIDCAP-certified nurse, blinded to the preterm infants' group assignment, carried out all assessments based on video recordings. In paper IV, HR and Oxygen Saturation $\left(\mathrm{SaO}_{2}\right)$ were also measured using a cardiorespiratory monitor (Hewlett Packard, Böblingen, Germany) prior to and during NPS, as well as 5, 10, 15, 20, and 25 minutes after the intervention (preterm infant population paper IV).

\section{Statistics}

\section{Cortisol Circadian Rhythm}

IBM SPSS Statistics software (version 19, 21 and 23) was used for statistical analysis. Statistical significance was considered at $\mathrm{p}<0.05$. In papers I-III CCR was considered to be present when infants, considered as a group in a specific month, had developed a cortisol pattern in which the median morning cortisol level was significantly higher than the median evening cortisol level. Samples were obtained on two consecutive days each month, and prior to analysis, averages were calculated from these two morning and evening levels for each infant and month. To avoid weighting certain individuals higher as a result of large interindividual differences in absolute cortisol concentrations, an evening/morning cortisol index was calculated for each individual by dividing the evening cortisol value by the morning cortisol value on that particular day. Subsequently the morning and evening levels were compared using the Wilcoxon rank-sum test for each months. By creating an evening/morning cortisol index for each individual, and by using nonparametric statistics, potential outliers did not have to be excluded. To determine how material was distributed, we performed the Kolmogorov-Smirnov Test using the data from morning, noon, and evening cortisol levels in papers I-IV, and also on evening/morning cortisol index values 
for papers I-III. Cortisol levels from papers I-III were not normally distributed, but they were in paper IV. We had used parametric analyses for paper IV, which was chronologically the first article written, before becoming aware that the cortisol levels in papers I-III were not normally distributed. In papers I and II the cortisol evening/morning indices showed a normal pattern of distribution, unlike the indices for paper III, for which reason these data were subjected to logarithmic adjustment based on natural logarithms. In paper IV, distribution of cortisol reactivity was normal in both preterm and full-term infants (Kolmogorov-Smirnov test). No outliers were found; all cortisol values (baseline, response, and reactivity) were within mean \pm 3 SD.

\section{Area under the curve}

Total AUC was analyzed as a rough measure of total basal cortisol secretion, based on the three mean values for morning, noon and evening measurements according to Pruessner et al. [188], expressed as nmol/L $\times$ h. The Kruskal Wallis test was used to calculate potential differences between infants at high psychosocial risk, healthy full-term infants and preterm infants. Monthly mean AUC levels were compare in each individual month (months two to twelve). An ANOVA with repeated measures was used to investigate potential difference between monthly AUC mean levels months two to twelve in the infants' at high psychosocial risk.

\section{Cortisol circadian rhythm in relation to the Hagadal daycare attachment program}

A linear Analyze of Variance (ANOVA) with repeated measures was used to analyze possible changes in CCR development among infants at high psychosocial risk, between week one and week six, before and after the Hagadal daycare attachment program (paper III). Since the age of all infants increased by at least one month and month of inclusion varied among the children, corrected age was used in the model. Possible confounding factors were listed in the model. 


\section{Gestational age vs postnatal age}

Papers I and II addressed three age groups: preterm infants (paper II), who were divided according to GA at birth into two groups, $<28$ weeks and 28-32 weeks, and the third group, full-term healthy infants (paper I), GA 37-42 weeks. Linear regression was applied to repeated measurements to calculate potential differences in development of CCR among the three different GA groups. Furthermore, a general linear model (ANOVA) was used to investigate CCR development (logarithms of evening/morning index, dependent variable) in relation to infant GA (measured in days, independent variable) (papers I-II).

\section{Salivary cortisol levels}

Papers I-III present monthly median salivary cortisol levels (quartile 1 - quartile 3) for the different infant study groups: healthy full-term infants, preterm infants, and infants at high psychosocial risk. Paper IV preterm and full-term infants median salivary cortisol levels (quartile 1 - quartile 3) at baseline and response sampling in the morning and in the afternoon.

\section{Individual Cortisol Circadian Rhythm}

The material relating to individual CCR development (papers I-III) during the infants' first year of life used a 20\%-difference as a cut-off, a limit based on the accuracy of the method and in line with cut-off limits used in other studies $[65,67,70]$.

\section{Regularity measured using the baby and behavior questionnaire}

A general linear model using repeated measurements was used to test for a potential increase in BBQ regularity between months one, six, and twelve (papers I-II) and months three, six, and twelve (paper III). Spearman's correlation analysis was used to compare the BBQ Regularity item with the evening/morning salivary cortisol index (papers I-III) in order to test the hypothesis postulating correlation between BBQ Regularity and development of CCR. Additionally, paper III calculates and presents the mean (SD) BBQ Regularity item for each month (months 2-12). 


\title{
Life incidence of traumatic events checklist
}

Spearman's correlation analysis was used to compare traumas registered through LITE with the evening/morning salivary cortisol index (papers I-III) in order to test the hypothesis postulating correlation between traumatic life events and the development of CCR. The analysis was performed in months one, six and twelve in paper I and II and in months six and twelve in paper III.

\begin{abstract}
Ainsworth
Mean difference between weeks one and six (before and after the Hagadal daycare attachment program) was calculated, as was effect size of the difference. A linear ANOVA model with repeated measurements between weeks one and six was used to analyze maternal sensitivity toward infants in the clinical-group, as measured by the Ainsworth sensitivity scale. Since the age of all infants increased by at least one month and month of inclusion varied among the children, corrected age was used in the model. The possible confounding factors described earlier were analyzed.
\end{abstract}

\section{Reactivity in cortisol Baseline - Response to oral glucose and nasopharyngeal suctioning}

The paired sample t-test was used to analyze possible differences in paired data, while the independent sample t-test was used to test differences between two groups (preterm vs. full-term), while the Kruskal-Wallis one-way ANOVA was used for three groups (preterm receiving glucose, preterm not receiving glucose, and full-term infants) (paper IV).

The Wilcoxon matched-pair signed-rank test was used to calculate VAS and recovery time. In the general linear models, cortisol reactivity was considered the dependent variable, while group (preterm/full-term), glucose administration (yes/no) and intervention time (morning/afternoon) were independent variables. To correct for individual variations in baseline cortisol, the change from baseline was dichotomized as either "decreased" or "increased" in order to ascertain the proportion of infants who showed either a decrease or increase (regardless of cortisol at baseline). At least a 10\% change from baseline salivary 
cortisol was required to be considered either an increase or decrease. A binomial test was used to calculate possible differences within the dichotomized variable (paper IV).

\section{Ethical approval}

The local ethics committee at Linköping University approved all studies. A single application (D\# M196-06) covered papers I-III, while a separate application applied to paper IV (D\# 03-427). Written informed consent was obtained from the parents of all infants. 
RESULTS

\section{RESULTS}




\section{Development of salivary cortisol circadian rhythm}

The result was based on a total of 14,168 salivary cortisol samples from 206 infants: CCR was considered to be present when morning cortisol levels were significantly higher than evening levels.

- 130 healthy full-term infants (paper I) developed CCR in month one, 8800 samples (figure 1a).

- 51 preterm infants (paper II) developed CCR in month one CA, 4164 samples (figure 1b).

- Intervention group I: 25 infants at high psychosocial risk (paper III) had already developed CCR by the time of inclusion in month two, 1204 samples (figure 1c).

- Intervention group II: 22 infants, including 11 preterm and 11 full-term (paper IV) did not vary by sampling time; consequently no signs of CCR were detected in this material. Samples were taken from preterm infants of GA 29-39 weeks (PNA varied from 4-86 days) and from healthy full-term control infants of GA 37-43 weeks on day 2-4 PNA. 
Figure 1a. Healthy Full-term Infants Cortisol Circadian Rhythm

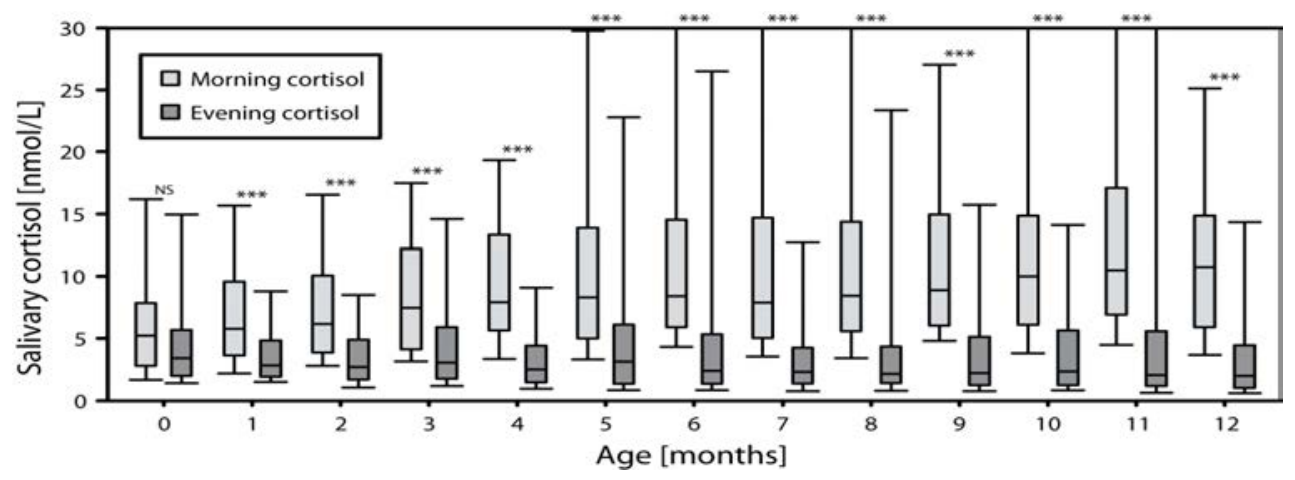

Figure 1b. Preterm Infants Cortisol Circadian Rhythm

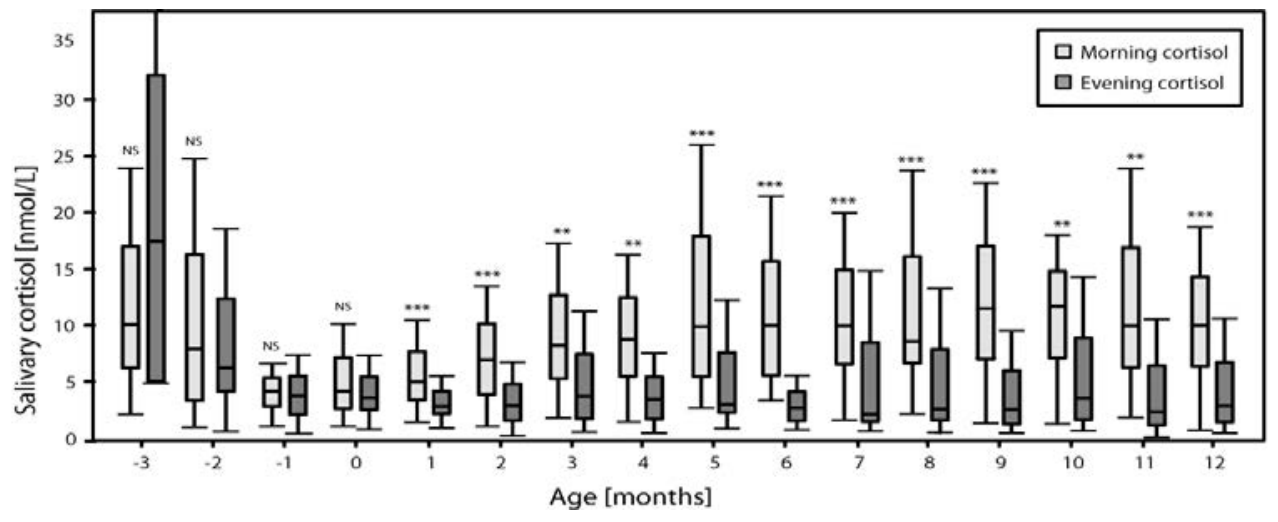

Figure 1c. Infants at High Psychosocial Risk Cortisol Circadian Rhythm

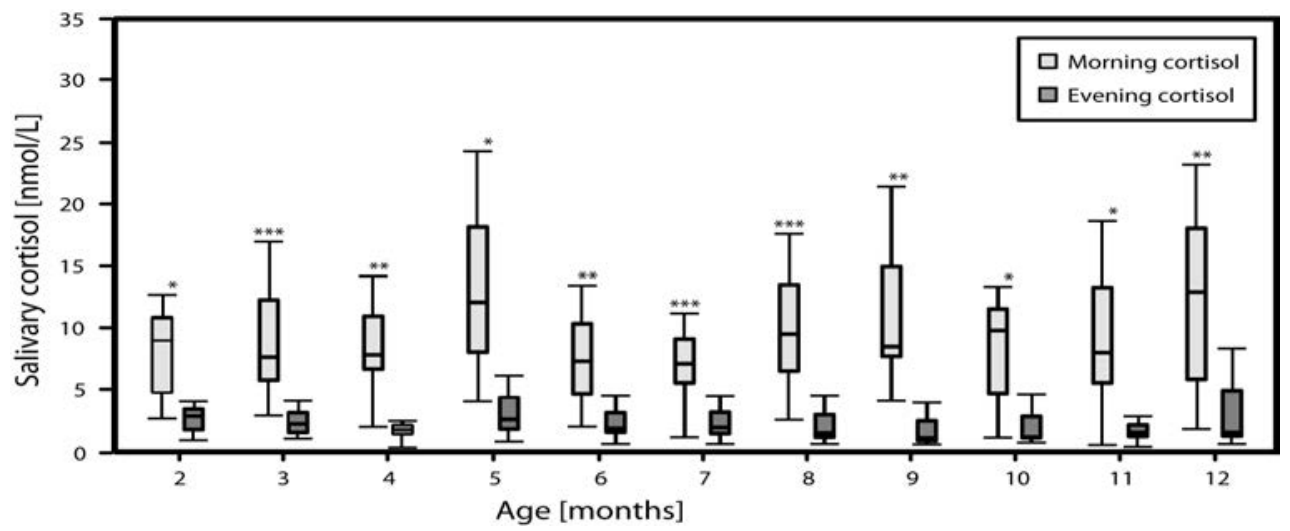

Figure 1 a-c. Boxplots: Light grey $=$ morning, dark grey $=$ evening; monthly cortisol median, inter-quartile range one and three. Non-parametric pairwise Wilcoxon rank-sum test was used to calculate potential differences between evening and morning salivary cortisol levels for each months. ${ }^{* * *}=\mathrm{P}<0.0001,{ }^{* *}=\mathrm{P}<0.001, *=\mathrm{P}<0.01$. 


\section{Persistence and possible strengthening of salivary cortisol circadian rhythm during the first year of life:}

CCR persisted throughout the first year of life and became more pronounced over time, with a monthly decrease in evening/morning index.

- Healthy full-term infants (paper I): CCR persisted and became more pronounced in months one to twelve, PNA (figure 2a).

- Preterm infants (paper II): CCR persisted and became more pronounced in months one to twelve, CA (figure $2 \mathrm{~b}$ ).

- Infants at high psychosocial risk (paper III): CCR persisted but did not strengthen during the study period, months two to twelve (figure 2c). 
Figure 2a-c. Individual development of cortisol circadian rhythm

Healthy full-term infants, $(\mathrm{n}=68)$; Preterm infants $(\mathrm{n}=51)$; Infants at high psychosocial risk $(\mathrm{n}=25)$.

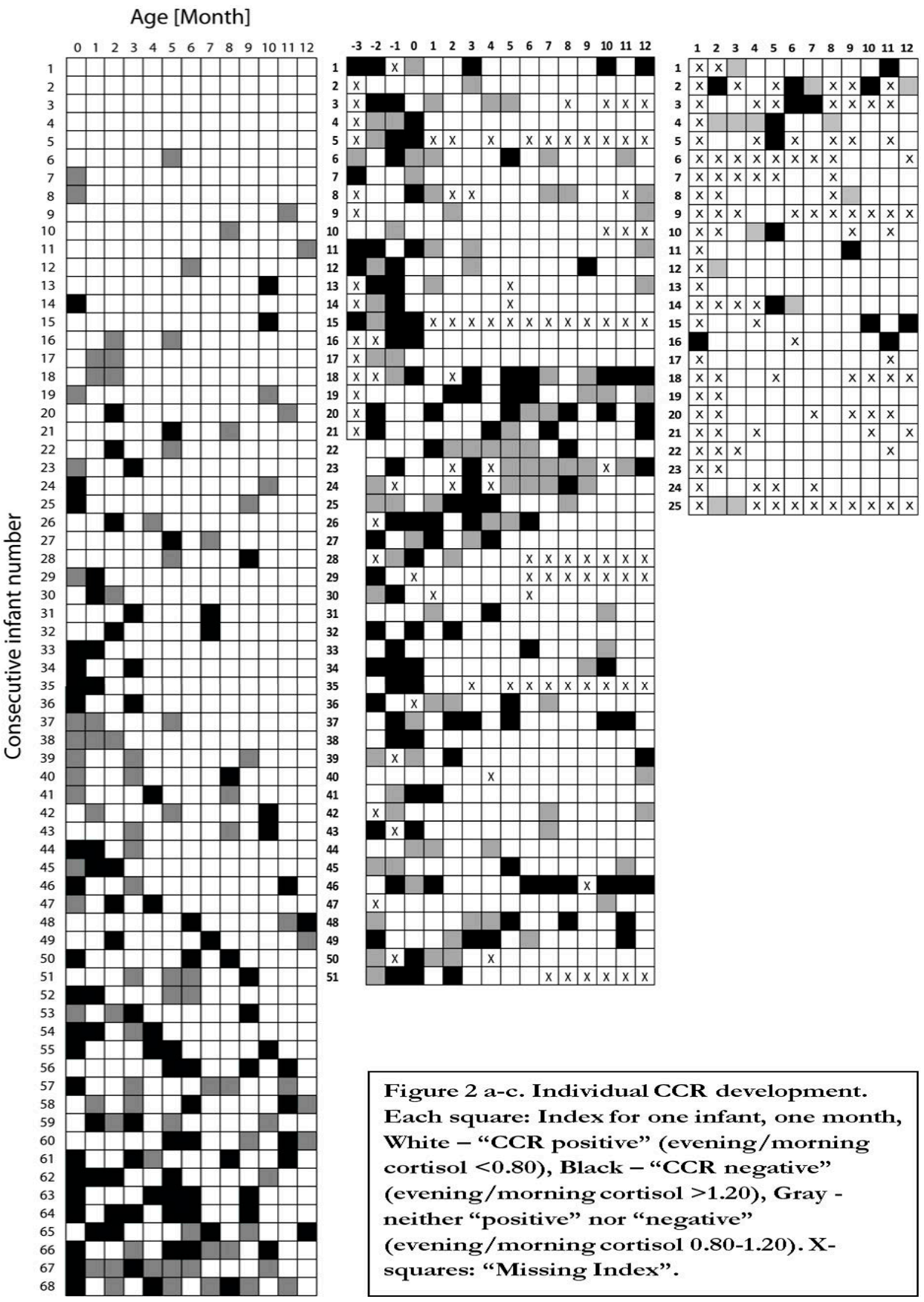




\section{Cortisol circadian rhythm development among preterm and full-term infants was dependent on gestational age rather than postnatal age}

- Mean evening/morning indices in two different groups of preterm infants (paper II) and one group of full-term infants (paper I): preterm infants GA $<28$ weeks 0.722, preterm infants GA 28-32 weeks 0.642, and healthy full-term infants GA 3742 weeks 0.563 .

- The difference was significant between each of the two preterm infant groups and the full-term infants $(\mathrm{p}=0.000$ and $\mathrm{p}=0.004$, respectively) and between the two preterm infant groups $(\mathrm{p}=0.025)$ (papers I-II).

- CCR development in relation to GA (papers I-II), measured in days, showed that CCR became more pronounced with higher GA.

- Infants with higher GA developed CCR at a lower PNA than infants with lower GA.

- Controlling for PNA, the results show that CCR development is dependent on infant GA rather than PNA.

- The decrease in evening/morning cortisol index was 0.02 per day of increased GA, given the same PNA in healthy full-term and preterm infants.

\section{Comments concerning possible confounding factors for development of cortisol circadian rhythm}

\section{Topical cortisone medication}

- The evening/morning index among infants with TCM (papers I-II) was 0.2 higher compared with infants without TCM from the same month. CCR development among infants who received occasional intermittent treatment with TCM was delayed by a statistically significant difference $(\mathrm{p}=0.016)$.

- Among infants at high psychosocial risk (paper III) only one infant received TCM treatment (ointment) during only one month (infant 15 month 12 figure 2). Although CCR had been present in earlier months prior to treatment, this infant 
displayed no CCR in month twelve (month of treatment). Cortisol levels were average prior treatment but in month twelve (month of treatment), the cortisol concentrations were exceptionally high $(7.30=23.4 \mathrm{nmol} / \mathrm{L}, 10.00=218.7$ $\mathrm{nmol} / \mathrm{L}$, and $19.30=53.1 \mathrm{nmol} / \mathrm{L})$. Because the data from these three concentrations may have been influenced by TCM they were excluded from all further analyses.

- In paper IV no infant received treatment with TCM.

\section{Maternal smoking during pregnancy}

- The evening/morning index among infants of smoking mothers at high psychosocial risk (paper III) was 0.3 higher compared with infants of non-smoking mothers from the same group, a significant difference $(\mathrm{p}=0.016)$.

- Smoking/non-smoking mothers ratio: 3:22

\section{Data differences: social versus psychiatric reason for referral to Hagadal attachment program}

- Infants of mothers referred to Hagadal for social problems had a 0.2 higher CCR index than infants whose mothers were referred to Hagadal for psychiatric reasons, $(\mathrm{p}=0.014)$.

\section{Psychological counseling during pregnancy}

- Infants whose mothers did not receive psychological counseling during pregnancy had a 0.2 higher CCR index than infants whose mothers did receive such counseling $(\mathrm{p}=0.013)$.

\section{Salivary cortisol levels}

Salivary cortisol levels are presented for healthy full-term infants, preterm infants, infants at high psychosocial risk, and preterm infants in intervention group II. Cortisol concentrations did not show a normal pattern of distribution in papers I-III for which reason median values and Q1-Q3 data are presented, along with the results from nonparametric statistical analyses (table 1a-d). 
Table 1a. Salivary cortisol levels in full-term infants and differences in evening/morning cortisol levels

\begin{tabular}{llllllllc}
\hline Age & & \multicolumn{2}{l}{ Morning levels 7:30 } & \multicolumn{2}{l}{ Noon levels 10:00 } & \multicolumn{2}{l}{ Evening levels 19:30 } & Differences \\
\cline { 5 - 8 } Month & $\mathbf{n}$ & Median & Q1-Q3 & Median & Q1-Q3 & Median & Q1-Q3 & P-value \\
\hline $\mathbf{0}$ & 95 & 5.1 & $2.8-8.2$ & 5.0 & $3.7-8.6$ & 3.4 & $2.1-5.7$ & 0.226 \\
$\mathbf{1}$ & 120 & 5.8 & $3.7-9.8$ & 4.8 & $2.8-6.8$ & 2.8 & $1.9-4.8$ & 0.000 \\
$\mathbf{2}$ & 121 & 6.1 & $3.9-9.8$ & 5.2 & $3.4-7.3$ & 2.7 & $1.7-4.9$ & 0.000 \\
$\mathbf{3}$ & 114 & 7.5 & $4.2-11.9$ & 5.9 & $4.1-8.5$ & 3.3 & $1.9-5.9$ & 0.000 \\
$\mathbf{4}$ & 118 & 8.0 & $5.7-13.5$ & 6.2 & $3.7-9.0$ & 2.5 & $1.5-4.4$ & 0.000 \\
$\mathbf{5}$ & 111 & 8.3 & $5.0-13.8$ & 5.9 & $3.5-8.6$ & 3.1 & $1.3-6.2$ & 0.000 \\
$\mathbf{6}$ & 112 & 8.9 & $6.2-14.9$ & 5.4 & $3.9-8.8$ & 2.3 & $1.3-5.0$ & 0.000 \\
$\mathbf{7}$ & 112 & 7.7 & $5.0-14.6$ & 5.1 & $3.6-8.1$ & 2.3 & $1.4-4.2$ & 0.000 \\
$\mathbf{8}$ & 107 & 8.4 & $5.6-14.2$ & 5.9 & $3.5-10.6$ & 2.2 & $1.4-4.3$ & 0.000 \\
$\mathbf{9}$ & 105 & 8.9 & $6.0-14.8$ & 5.6 & $3.6-9.9$ & 2.3 & $1.2-5.2$ & 0.000 \\
$\mathbf{1 0}$ & 107 & 10.0 & $6.1-14.2$ & 5.4 & $3.7-8.9$ & 2.4 & $1.3-5.6$ & 0.000 \\
$\mathbf{1 1}$ & 106 & 10.5 & $6.9-17.1$ & 5.3 & $3.4-9.7$ & 2.1 & $1.2-5.6$ & 0.000 \\
$\mathbf{1 2}$ & 107 & 10.9 & $5.9-14.4$ & 5.2 & $3.1-8.6$ & 2.0 & $1.1-4.2$ & 0.000 \\
\hline
\end{tabular}

Monthly median (Q1-Q3) salivary cortisol values $[\mathrm{nmol} / \mathrm{L}]$ at three different sampling times: morning (07.30-09.30), noon (10.00-12.00) and evening (19.30-21.30). Monthly pvalues for difference between evening and morning cortisol on a group level using Wilcoxon's rank-sum test. Age for sampling measured in: Month for sampling during full-term infants' first year of life. Number (n) of infants that submitted analyzable samples for evening/morning range in each month.

Table 1b. Salivary cortisol levels in preterm infants and differences in evening/morning cortisol levels

\begin{tabular}{|c|c|c|c|c|c|c|c|c|}
\hline \multicolumn{2}{|l|}{ Age } & \multicolumn{2}{|c|}{ Morning levels 7:30 } & \multicolumn{2}{|c|}{ Noon levels 10:00 } & \multicolumn{2}{|c|}{ Evening levels 19:30 } & \multirow{2}{*}{$\begin{array}{l}\text { Differences } \\
\text { P-value }\end{array}$} \\
\hline Month & $\mathrm{n}$ & Median & Q1-Q3 & Median & Q1-Q3 & Median & Q1-Q3 & \\
\hline-3 & 7 & 10.0 & $6.2-16.7$ & 11.3 & $7.1-14.8$ & 17.1 & $5 . .0-31.5$ & $0.043^{*}$ \\
\hline-2 & 45 & 7.8 & $3.4-16.0$ & 6.0 & $3.5-13.1$ & 6.2 & $4.2-12.2$ & 0.569 \\
\hline-1 & 46 & 4.2 & $2.9-5.4$ & 3.8 & $2.8-5.5$ & 3.8 & $2.2-5.5$ & 0.723 \\
\hline 0 & 49 & 4.2 & $2.7-7.1$ & 4.1 & $2.6-6.1$ & 3.6 & $2.6-5.4$ & 0.574 \\
\hline 1 & 48 & 5.0 & $3.4-7.6$ & 4.0 & $3.0-6.5$ & 2.9 & $2.2-4.2$ & 0.000 \\
\hline 2 & 45 & 6.9 & $3.9-10.1$ & 4.6 & $3.2-7.6$ & 2.9 & $1.7-4.8$ & 0.000 \\
\hline 3 & 48 & 8.2 & $5.3-12.5$ & 5.9 & $3.3-12.0$ & 3.8 & $1.8-7.4$ & 0.003 \\
\hline 4 & 45 & 8.7 & $5.5-12.3$ & 6.9 & $5.0-8.7$ & 3.5 & $1.8-5.5$ & 0.001 \\
\hline 5 & 47 & 9.8 & $5.5-17.6$ & 6.1 & $4.5-10.5$ & 3.1 & $2.3-7.6$ & 0.000 \\
\hline 6 & 45 & 9.9 & $5.6-15.4$ & 5.1 & $4.2-6.8$ & 2.8 & $1.6-4.1$ & 0.000 \\
\hline 7 & 45 & 9.8 & $6.5-14.7$ & 5.3 & $3.2-9.2$ & 2.2 & $1.6-8.4$ & 0.000 \\
\hline 8 & 44 & 8.5 & 6.6-15.8 & 5.9 & $4.5-10.1$ & 2.7 & $1.7-7.8$ & 0.000 \\
\hline 9 & 44 & 11.3 & $7.0-16.7$ & 4.8 & $3.4-7.8$ & 2.6 & $1.3-6.0$ & 0.000 \\
\hline 10 & 42 & 11.5 & 7.1-14.6 & 5.0 & $2.9-9.0$ & 3.6 & $1.7-8.8$ & 0.001 \\
\hline 11 & 42 & 9.9 & 6.3-16.6 & 4.9 & $2.9-10.7$ & 2.4 & $1.3-4.4$ & 0.001 \\
\hline 12 & 43 & 9.9 & 6.3-14.1 & 4.5 & $3.1-9.0$ & 2.9 & $1.5-6.7$ & 0.000 \\
\hline
\end{tabular}

Monthly median (quartile 1 - quartile 3) salivary cortisol levels [nmol/L] at three different sampling times: morning (07:30-09:30), noon (10:00-12:00) and evening (19:30-21:30). Corrected Age in months: minus three to twelve, (month: $-3=$ gestational week 28, $-2=$ gestational week $32,-1=$ gestational week 36 and $0=$ gestational week 40 ). Monthly pvalues for difference between evening and morning cortisol on a group level using Wilcoxon's rank-sum test. Number (n) of infants that submitted analyzable samples for evening/morning range in each month. 
Table 1c. Salivary cortisol levels in infants at high psychosocial risk and differences in evening/morning cortisol levels

\begin{tabular}{|c|c|c|c|c|c|c|c|c|}
\hline \multicolumn{2}{|l|}{ Age } & \multicolumn{2}{|c|}{ Morning levels 7:30 } & \multicolumn{2}{|c|}{ Noon levels 10:00 } & \multicolumn{2}{|c|}{ Evening levels 19:30 } & \multirow{2}{*}{$\begin{array}{l}\text { Differences } \\
\text { P-value }\end{array}$} \\
\hline Month & $\mathrm{n}$ & Median & Q1-Q3 & Median & Q1-Q3 & Median & Q1-Q3 & \\
\hline $1 *$ & 1 & $3.1^{*}$ & & $2.0^{*}$ & & $5.2^{*}$ & & \\
\hline 2 & 12 & 9.9 & $4.6-13.5$ & 4.4 & $3.7-6.5$ & 3.0 & $1.7-4.6$ & 0.010 \\
\hline 3 & 19 & 8.9 & $6.1-16.2$ & 5.3 & $3.6-9.1$ & 2.2 & $1.5-3.4$ & 0.000 \\
\hline 4 & 16 & 8.4 & $6.5-12.2$ & 7.5 & $3.6-9.2$ & 2.0 & $1.4-3.0$ & 0.001 \\
\hline 5 & 18 & 12.5 & $8.6-20.0$ & 8.3 & $5.5-11.7$ & 2.8 & $1.7-5.6$ & 0.039 \\
\hline 6 & 20 & 7.2 & $4.5-11.3$ & 8.4 & $6.3-11.8$ & 2.4 & $1.5-3.8$ & 0.006 \\
\hline 7 & 20 & 7.0 & $5.5-9.8$ & 6.9 & $5.2-7.8$ & 2.1 & $1.4-3.9$ & 0.000 \\
\hline 8 & 17 & 10.0 & $6.4-14.6$ & 4.2 & $3.6-7.7$ & 1.4 & $1.0-3.2$ & 0.000 \\
\hline 9 & 16 & 8.4 & $7.2-14.9$ & 4.8 & $3.2-8.4$ & 1.1 & $0.8-2.5$ & 0.007 \\
\hline 10 & 19 & 10.5 & 4.6-11.5 & 5.5 & $3.6-8.8$ & 1.6 & $1.0-7.8$ & 0.010 \\
\hline 11 & 15 & 8.0 & $5.5-15.3$ & 4.4 & $2.8-9.3$ & 1.5 & $1.1-2.2$ & 0.012 \\
\hline 12 & 21 & 11.7 & $5.4-19.0$ & 4.7 & $2.9-7.8$ & 1.9 & $1.2-5.1$ & 0.001 \\
\hline
\end{tabular}

Monthly median (quartile 1 - quartile 3) salivary cortisol levels [nmol/L] at three different sampling times: in the morning (07:30), at noon (10:00) and in the evening (19:30). * The salivary cortisol levels in month one are representing one infant. Monthly $\mathrm{p}$-values for difference between evening and morning cortisol on a group level using Wilcoxon's ranksum test. Age for sampling measured in: Month for sampling during infants' at high psychosocial risk during (month 1-12) first year of life. Number (n) of infants that submitted analyzable samples for evening/morning range in each month.

Table 1d. Salivary cortisol baseline levels in preterm infants and full-term infants in morning and afternoon total 44 samples

\begin{tabular}{|c|c|c|c|c|c|c|c|}
\hline \multirow[t]{2}{*}{ Infants } & & \multirow{2}{*}{$\begin{array}{l}\text { Born in } \\
\text { gestational } \\
\text { age } \\
\begin{array}{l}\text { Mean } \\
\text { (week+days) }\end{array}\end{array}$} & \multirow{2}{*}{$\begin{array}{l}\text { Sampling age } \\
\text { Gestational age } \\
\text { respectively } \\
\text { Postnatal age days } \\
\text { Mean (week+days) } \\
\text { mean(SD) (days) }\end{array}$} & \multicolumn{2}{|c|}{$\begin{array}{l}\text { Morning levels } \\
\text { 08:00-10:00 }\end{array}$} & \multicolumn{2}{|c|}{$\begin{array}{l}\text { Afternoon levels } \\
\text { 12:00-16:00 }\end{array}$} \\
\hline & $\mathbf{n}$ & & & Median & Q1-Q3 & Median & Q1-Q3 \\
\hline Preterm infants & 11 & $28+2$ & $32+3$ & 13.3 & $4.6-26.8$ & 9.0 & $5.3-24.7$ \\
\hline Full-term infants & 11 & $40+4$ & $2.6(0.6)$ & 10.8 & $6.2-13.4$ & 5.8 & $4.3-20.3$ \\
\hline
\end{tabular}

Baseline cortisol samples at one occasion. Median (quartile 1 - quartile 3) salivary cortisol levels [nmol/L] at two different sampling times: in the morning (08:00-10:00) and in the afternoon (12:00-16:00). Age for sampling in full-term infants measured in postnatal days, mean day, in preterm infant group measured in gestational age, resembling corrected age (paper IV). 
Development of regularity among infants during the first year of life, as measured by the baby and behavior regularity item

- Full-term infants, paper I: developed increasing regularity during the first year of life both between months one and six $(\mathrm{p}=0.000)$ and between months six and twelve $(\mathrm{p}=0.000)$, PNA.

- Preterm infants, paper II: developed increasing regularity during the first year of life both between months one and six $(\mathrm{p}=0.000)$ and between months six and twelve $(\mathrm{p}=0.000)$, CA.

- Infants at high psychosocial risk, paper III: developed increasing regularity between months three and six $(\mathrm{p}=0.024)$, but not between months six and twelve $(\mathrm{p}=0.124)$, PNA.

\section{Possible correlation between the baby and behavior questionnaire regularity and development of cortisol circadian rhythm}

- Full-term infants, paper I: no correlation between BBQ mean regularity and evening/morning cortisol index in months one, six, and twelve, PNA.

- Preterm infants, paper II: no correlation between BBQ mean regularity and evening/morning cortisol index in months one, six, and twelve, CA.

- Infants at high psychosocial risk, paper III: no correlation between BBQ mean regularity and evening/morning cortisol index in months three, six, and twelve, PNA. 


\section{Possible correlation between traumas as measured using the Life incidence of traumatic events checklist and development of cortisol circadian rhythm}

- Full-term infants, paper I: no correlation between LITE and evening/morning cortisol index months one, six, and twelve, PNA.

- Preterm infants, paper II: no correlation between LITE and evening/morning cortisol index months one, six, and twelve, CA.

- Infants at high psychosocial risk, paper III: no correlation between LITE and evening/morning cortisol index months six and twelve, PNA.

\section{Intervention I}

\section{Impact of Hagadal daycare attachment program}

- Caregivers of infants at high psychosocial risk, paper III: Ainsworth sensitivity scale, score increased from 3.9-4.8 with effect size 0.86 between weeks one and six $(p=0.049)$ when adjusted for age.

- Infants at high psychosocial risk, paper III: Progress in CCR development was detected with a significant decrease in salivary evening/morning cortisol index between weeks one and six when corrected for age $(p=0.026)$.

\section{Intervention II}

Possible effects of nasopharyngeal suctioning and possible effects of $30 \%$ oral glucose treatment

- 11 Preterm infants intervention group, Paper IV: Possible influence of oral glucose treatment on baseline cortisol levels - no significant difference in baseline salivary cortisol levels with or without oral glucose treatment (before intervention).

- 11 Preterm infants intervention group, Paper IV: Change from baseline cortisol in response to NPS with oral glucose treatment - no significant difference from baseline salivary cortisol in response to NPS with oral glucose treatment. 
- 11 Preterm infants intervention group, Paper IV: Change from baseline cortisol in response to NPS without oral glucose treatment - no significant difference from baseline salivary cortisol in response to NPS without oral glucose treatment.

- 11 Full-term infants intervention group, Paper IV: Possible change from baseline cortisol in response to NPS without oral glucose treatment - no significant difference from baseline salivary cortisol in response to NPS without oral glucose treatment.

- 11 Preterm infants intervention group, Paper IV: Difference in VAS, HR, $\mathrm{SaO}_{2}$ or recovery time in response to NPS with oral glucose treatment - no significant difference in VAS, HR, $\mathrm{SaO}_{2}$ or recovery time before and after NPS with oral glucose treatment.

- 11 Preterm infants intervention group, Paper IV: Difference in VAS, HR, $\mathrm{SaO}_{2}$, or recovery time in response to NPS without oral glucose treatment - no significant difference in VAS, $\mathrm{HR}, \mathrm{SaO}_{2}$ or recovery time before and after NPS without oral glucose treatment. 


\section{DISCUSSION}

\section{Development of salivary cortisol circadian rhythm}

The development of CCR in infants was investigated for one full year in three different groups of infants: healthy full-term infants, preterm infants, and infants at high psychosocial risk. Our results, based on a total of 14,168 samples from 206 infants, are clearly represent the largest investigation to date within this young population of infants, from birth to age twelve months.

As a group, healthy full-term infants developed CCR with a significantly higher level of morning cortisol than evening cortisol in month one, whereas preterm infants as a group developed a pattern resembling significant CCR in month one CA (figure 1a-b). Development of CCR in preterm infants was dependent on GA rather than PNA. The group of infants at high psychosocial risk showed persistent CCR beginning the first month of investigation (month two) that persisted until month twelve (figure 1c).

Seven earlier studies have investigated development of salivary CCR in full-term infants [61-67] and an additional seven studies have investigated CCR development in preterm infants [68-74] (saliva, plasma, or serum), whereas only one study has examined CCR in high psychosocial risk infants at < twelve months of age [100] (saliva).

Among healthy full-term infants, results pertaining to development of CCR were highly divergent, requiring from 7.4 weeks to more than 9 months to appear. Our sampling times and CCR results were similar to the studies presented by Price (1983), Santiago (1996), and Custodio (2007), while other studies did not include sampling during the first month of life $[64,66]$ when CCR was established. One factor common to earlier studies was the small number of subjects, in two cases relying on just a single observation, thereby risking unreliable conclusions [62, 63]. The primary focus was not necessarily on CCR development [64]. The results from studies on preterm infants were either in line with ours regarding time for onset of CCR [70,74], or the studies were not designed to cover that time period (one month CA) [68, 69, 71-73]. De Weerth et al. investigated the dynamics of cortisol levels among infants age nine months, with risk factors similar to our group of 


\section{DISCUSSION}

infants at high psychosocial risk, and concluded that high maternal stress predicts high infant cortisol levels with high total AUC; our findings of high variability in AUC along with CCR curves that do not flatten over time are consistent with these results. High maternal cortisol levels during pregnancy are accompanied by elevated in utero cortisol levels that affect the fetus, which may have developmental implications [100].

In paper IV cortisol samples were collected in the morning and in the afternoon and because of the theoretical possibility of diurnal influences the material was controlled for sampling time differences (table 1d). Among these newborn preterm and full-term infants there were no signs of CCR, findings that are consistent with normal development of CCR later in month one, as found in papers I and II. The subjects in paper IV have no CCR, likely due to their young age. Overall variability in salivary cortisol levels in both directions was quite high among the infants in paper IV. All samples were collected on the same day and not for the purpose of investigating CCR development. Viewing our results in relation to CCR development and comparing them with the diversity of approaches and results from earlier studies entailing a) infants at early age (<three weeks PNA) [69, 71, 73], b) small samples (<14 infants) [61, 65, 66, 70], or c) single day sampling [63, 64], the importance of consistency, frequency, and sampling regularity in mapping the natural course of CCR development becomes apparent, as do the advantages of a larger consistent study material. Our material shows that CCR develops during the first month of life and follows the natural biological course of infant growth. Some preterm infants were found to have high baseline cortisol and their ability to further increase cortisol secretion in response to CPAP treatment may have been limited due to already elevated baseline values resulting from stress [189]. The substantial difference in mean age of preterm (28 days) and full-term (64h) infants (table 1d) may be a possible limitation because CCR development depends on GA, which in turn exerts influence on baseline cortisol levels (table 1a-b).

\section{Development of cortisol circadian rhythm dependent on gestational age}

CCR development was found to depend on infant GA rather than PNA (papers I-II). Scott et al. assumed CCR to be a dependent variable in relation to GA, although their study did 
not cover the period of CCR development [73]. These data have now been confirmed: our results show that CCR development in relation to GA (measured in days) increases with higher GA and that infants of higher GA develop CCR at a lower PNA than infants of lower GA. CCR develops in preterm infants (paper II) at one month CA, confirming that CCR is GA-dependent. CCR at one month CA in preterm infants resembles CCR at one month PNA in full-term infants (paper I). Maturation of the adrenal cortex in preterm infants relates to GA [29] and GA in preterm infants predicts perinatal morbidity, delayed maturation of lung function, and state of health, as well as illness and concentration difficulties later in life [29-31, 158, 190].

\section{Cortisol circadian rhythm develops and becomes more pronounced with time}

Once CCR had developed at age one month (papers I-III), it persisted throughout the first year of life. Cortisol levels (table 1a-d) stabilized over time with increases in the morning and decreases in the evening, resulting in a more pronounced CCR month by month and accompanied by a decrease in the evening/morning cortisol index among full-term infants from month one (paper I) and preterm infants from month one CA (paper II). Among infants at high psychosocial risk (paper III) CCR was present and persisted, albeit with a higher degree of variability; however, the expected further development of CCR failed to occur when the Hagadal daycare attachment program ended. No decrease or stabilization of monthly cortisol levels was reflected by the data in paper III. Higher variability is also found among preterm infants between GA 28 and 32 weeks and seems to be the result of both genetic and environmental factors. Although preterm infants are also considered at risk, their cortisol levels begin to stabilize between GA 36 and 40 weeks. Preterm infants are considered to be at higher risk than full-term infants due to their higher morbidity, mortality, maternal physical or psychological morbidity, maternal smoking and/or low SES [26, 27, 29-33, 36, 37]. Preterm infants also have higher cortisol levels during the first days after birth [71] compared with full-term infants, which is consistent with GA-dependent development of CCR. Our results, which represent a unique addition to the literature in this age group of infants at high psychosocial risk, show that such young infants are also at risk of long-term elevated cortisol levels and that CCR development, although present, is 


\section{DISCUSSION}

disturbed. It is well-known that younger infants have higher interindividual variations in absolute morning-evening cortisol indices $[65,67,69-71]$ and they also vary in basal cortisol levels both intraindividually and interindividually [191].

\section{Possible correlation between behavioral regularity and cortisol circadian rhythm}

The BBQ regularity item was used to detect possible development of regularity in infant habits during their first year of life. Full-term and preterm infants develop increasing regularity during their first year of life, while infants at high psychosocial risk display higher variability and no increasing regularity. We investigated the possibility of correlation between BBQ and development of CCR, but found none in either infant group (papers IIII), even though both full-term and preterm infants displayed an increase in both CCR and regularity over the first year of life. Infants at high psychosocial risk varied greatly with respect to regularity (as well as the previously mentioned CCR). Our results are in line with earlier studies, where no statistically significant association was found between sleeping pattern regularity and development of CCR, although six of eight infants developed CCR after they started sleeping through the night [61]. Moreover, sleep time increased in relation to CCR development at PNA week eight among preterm infants [70]. The observed lack of correlation between CCR and behavioral regularity may be because CCR depends on maturity of biological functions such as maturation of the adrenal cortex and other developmental functions that accompany increased GA [29], whereas regularity in behaviors such as sleep seems to be dependent on both GA and environmental influences, e.g. days at home or in hospital care [192].

\section{Cortisol in children at high psychosocial risk}

Earlier studies have investigated cortisol levels, cortisol AUC, and CCR in older children, age one to ten years. It is well-established that salivary cortisol in children correlates with family SES; low SES children are predisposed to high cortisol levels and also experience more stress $[93,101]$. These results are consistent with the continuously elevated cortisol levels found in our study in response to underlying psychosocial risk factors among 
caregivers. Increased cortisol levels among low SES children correlate with symptoms of depression [76, 93, 96], stress, or anxiety [102] among mothers, underscoring the need for a long-term solution to reduce psychosocial risk factors in these families. Both adults and adolescents with deviating CCRs (higher baseline levels and flatter slope) have retrospectively reported early childhood adversity [84, 103]. Our findings of higher variability in cortisol levels, higher basal cortisol levels, and less well-defined CCRs are consistent with earlier studies [76, 93, 101, 102], despite population differences in age. We may assume that without treatment, CCR development in these infants will continue to be disturbed with elevated baseline cortisol levels.

\section{Impact of attachment program - Intervention I}

The highly vulnerable group of infants at high psychosocial risk (paper III) are in need of early family treatment and support [97] and family therapy is a well-respected increasingly practiced form of therapy to support families at risk [133, 193]. Ainsworth sensitivity score increased during the six-week daycare program and CCR development improved (both adjusted for age). The current result thereby confirms earlier assessments $[75,121]$ that such daycare programs increase caregiver sensitivity to infant signals, as reflected by an increase in Ainsworth sensitivity scores which translates to enhance infant-caregiver attachment. Perhaps most importantly this study contributes new results that show how the infant CCR progresses during the six-week program. These findings confirm that the program helps these infants to stabilize CCR development, though surprisingly the monthly evening/morning cortisol index did not decrease as it did among the infants studied in papers I and II. The attachment program promotes CCR development in infants at high psychosocial risk, where they would otherwise be at a disadvantage compared with healthy full-term infants, which means that the program helps restore at-risk infants to a similar level of CCR development as that of their healthy peers. These results suggest that the increased caregiver sensitivity resulting from the attachment program serves a protective function, thereby confirming the need to create a healthy environment for the growing child [194, 195]. Caregiver-infant sensitivity along with genetic risk for insecure attachment govern development of attachment [195]. Consequently caregiver sensitivity is 


\section{DISCUSSION}

especially important where high genetic risk is present. Only insecurely attached infants show elevated cortisol levels in relation to SSP [97-99, 196].

\section{Impact of oral glucose during nasopharyngeal suctioning - Intervention II}

Oral glucose as an intervention (paper IV) had no impact on cortisol baseline levels before NPS, neither on the cortisol response levels after NPS nor on any of the measured pain or stress parameters, therefore oral glucose did not alter any results. Due to the lack of impact, we may conclude that NPS in this context is not a sufficiently painful stimulus to evoke a pain reaction in infants, to be eased by the analgesic benefit of glucose. Preterm infants have earlier exhibited altered HPA axis function at young ages (three, eight, and 18 months, as well as at seven years) $[160,161]$ and often but not always they react with elevated salivary cortisol levels [49]. Previously cortisol levels has been found to correlate with the degree of pain to which the infants were exposed to during the neonatal period [162-164].

Since sweet-tasting solution is recommended for preterm infants during several routine NICU procedures, [167] these results deserve consideration. Most research on sweettasting solutions for infants has focused on analgesic effects, but Holsti \& Grunau note the importance of considering both positive and possible negative effects to avoid overuse [197].

NPS is one of many NICU procedures; currently we do not know what possible long-term impact may result from invasive procedures at an early age. Research concerning potential stress from painful interventions is therefore highly pertinent in regard to possible developmental effects_-whether physical, cognitive, or psychological—among infants subjected to extensive activation of the HPA axis from stress and/or pain. 


\section{Confounding factors affecting development of cortisol circadian rhythm}

A variety of factors have previously been shown to affect CCR development in infants, leading to investigation of several possible confounding factors. TCM has previously been shown to affect cortisol levels in preterm infants with respiratory diseases [198, 199]. The data from papers I and II in our material shows a significant association between increased morning, noon, and evening cortisol levels and TCM use by individual infants, during each single month of medication use. Development of CCR was delayed among infants who were intermittently treated with TCM during occasional months (papers I-II). No prior study on CCR development in full-term or preterm infants has reported this interesting finding [61-74], which signals the need for further studies on this topic. Moreover, smoking among mothers of high psychosocial-risk infants (paper III) had a negative impact on CCR development. None of the mothers of infants studied in papers I, II, or IV smoked, for which reason we could not control for this variable. A 2006 study by McDonald et al. concluded that infants exposed to tobacco in utero had elevated ACTH levels [131] while Saridjan et al., noted an effect on cortisol variability among children age 14 months whose mothers smoked [101]. The number of smoking mothers were only three (all in paper IV) throughout the material and no mother used snuff. According to Swedish maternal statistics our mother reports lower level of maternal tobacco use than average [28]. Despite lower levels than aveage, there is a significant difference in CCR in relation tobacco use and this topic would be interesting to study further in a costume designed study. The number, intensity, and duration of risk factors have been shown to correlate with cortisol levels [143, 144], as has caregiver depression [96]. Social problems had a more negative impact on CCR development among infants in our study (paper III) than did psychiatric problems. One possible explanation was that families referred to Hagadal for social issues often were more heavily burdened with economic, social, and even coexisting psychiatric problems, than families referred for psychiatric issues, whose lifestyle may have functioned relatively well with an average standard of living and therefore fewer social and other risk factors. These data concerning potential protective factors are supported by the confounding factor of psychological counseling for mothers during pregnancy, which had a protective influence on the unborn infant as reflected by improved development of CCR. 


\section{DISCUSSION}

These findings suggest that psychological counseling may stabilize CCR development among infants participating in the attachment program.

\section{Life incidence of traumatic events}

No correlation was found between traumas, as detected through the LITE checklist, and CCR development in any of the different infant populations - healthy full-term infants, preterm infants, or infants at high psychosocial risk (papers I-III). One common denominator was that all three patient groups had very few reported traumas. In addition, a large number of questionnaire responses were missing among infants at high psychosocial risk. Previous studies have shown that traumas, especially multiple traumas in abused adolescents, influence salivary cortisol levels [127]. The number of traumatic events reported in our patient groups was insufficient to allow testing for possible multiple-trauma influence; one plausible explanation for the lack of significant correlation may be that most of these infants experienced few traumatic life events other than illness and hospitalization. 


\section{CONCLUSIONS}

The most important points contributed by this thesis to new knowledge concerning the scientific realm of stress in relation to salivary cortisol secretion in infants are:

- Cortisol circadian rhythm in healthy full-term infants can be detected as early as one month of age and becomes increasingly well-established throughout the first year of life.

- Cortisol circadian rhythm is present by one month corrected age in preterm infants and becomes increasingly well-established throughout the first year of life.

- Cortisol circadian rhythm in infants at high psychosocial risk was present upon study inclusion at two months of age and persists throughout the first year of life, but displays high variability and does not become increasingly well-established with age.

- Development of cortisol circadian rhythm is dependent on gestational age rather than postnatal age.

- The current thesis also provides new data concerning basal daytime salivary cortisol levels for healthy, full-term infants, preterm infants and infants at high psychosocial risk during the first year of life.

- Development of cortisol circadian rhythm was strengthened among infants who participated in the Hagadal daycare attachment program, which fostered caregiver sensitivity and improved caregiver-infant attachment.

- Topical cortisone medication (inhalation or ointment) as a confounding factor was found to be associated with elevated levels of cortisol and significant delay in development of cortisol circadian rhythm, as was maternal smoking. 
- Infants of mothers at high psychosocial risk who received prenatal maternal supportive counseling also displayed acceleration of cortisol circadian rhythm development.

- Nasopharyngeal suctioning was neither stressful nor painful enough to elicit a stress response as had been expected.

- Use of oral glucose as an analgesic to offset the expected stress elicited by nasopharyngeal suctioning did not alter cortisol levels since no stress response occurred.

The results of this thesis are based on extensive data pertaining to infant salivary cortisol secretion, and when taking into account the relatively large number of infants studied and regularity of long-term sampling, they underscore the reliability of the conclusions. We therefore believe that these new findings will prove useful for both clinical practice and further scientific research concerning the stress-reducing measures that are essential for improving healthy development in the growing child, especially among highly vulnerable infants. 


\section{ETHICAL CONSIDERATIONS}

In pediatric research in general we have to work according to high ethical standards and as in all research in accordance with the ethical considerations of the declaration of Helsinki. As all children are dependent on the caregiver for survival, especially at a young age $U N$ 's convention on the rights of the child is appropriate to have in mind. The newborn child and especially preterm infants, children suffering from serious illness and infants born in high psychosocial risk families are particularly vulnerable populations in research. The children, from birth until the age of 18 years are dependent on their parents' written consents for participating in scientific studies [200]. Thus we have to rely on the parents and therefore it is important that oral and written information is clear so that the parents can understand what it means to enroll their infant or young child in a clinical trial [200, 201]. With increasing age of the child and along with the development of the child's ability, he or she should always be a part of the dialogue that takes place between co-workers and parents concerning involvement in research studies.

It is known that preterm infants at NICU undergo several painful as well as handling procedures every day $[34,165,202]$. It is an ethical dilemma whether one can add further procedures to these already vulnerable infants in order to do research. On the other hand, there is still a lot to learn about preterm and/or sick infants in order to cure, find new treatments and ameliorate the care of these infants. Currently, there is limited scientific evidence for many of the treatments and technological innovations that are being introduced in neonatal care [201]. The investigated infants in paper IV were all in need of CPAP treatment and nasopharyngeal suctioning. Salivary sampling is not painful or stressful but still it means extra handling. The full-term healthy infants used as controls were not in need of the NPS but added important information to the result. So, one could consider if it is ethical not to perform important clinical research involving newborn infants as long as the ethical considerations of the declaration of Helsinki are considered.

To be able to minimize psychosocial burden and adequately handle risk management, supportive treatments/programs should be evaluated, preferably in a scientific manner. Caregivers of infants at high psychosocial risk need correct and understandable 
information about research which can be perceived as stressful but at the same time a way to secure that the healthcare develops according to scientific knowledge and evidence. Previously, mothers of hospitalized children have expressed their appreciation for the opportunity to participate in an interview study during a stressful time, since the interview helped them to sort things out [203].

In the present thesis research has been performed for the benefit of new knowledge in the field of stress and stress-reducing factors for infants. None of the procedures performed were in any way stressful or painful to the infants. In the papers presented the researchteam worked together for the beneficial of infants and parents. A careful and open dialogue has been present throughout the study-periods between the research-team and co-workers at the different clinics as well as with the included parents, to increase the sense of coherence and understanding. 


\section{ERRATA}

In paper I an unfortunate clerical error occurred which did not alter the conclusions of the published paper but needed a correction that was published [204]. The research assistant who entered the questionnaire form the baby and behavior questionnaire results interpreted the template in the opposite order of the one intended (points were entered 1 to 5 , where they should have been entered 5 to $1: 5=1,4=2,3=3,2=4$ and $1=5$ ). The data from the baby and behavior questionnaires were corrected and reentered in the raw data file, the results were corrected and all statistics recalculated. The baby and behavior questionnaire regularity item increased significantly over the months covered by the study. There were no significant development of negative correlation (Spearman) monthly on infants in single months. For more information see the correction [204]. 
ERRATA

54 


\section{LIMITATIONS}

Larger study populations is often a better base for a more solid conclusion, as in our study regarding cortisol levels for e.g. preterm infants, infants at high psychosocial risk and the oral glucose intervention study. Sampling frequency is a limitation in our study as in many others. As cortisol levels peak in the morning and reach a nadir in the evening we chose sampling times to fit this pattern, but an entire 24-hour cortisol cycle would possibly have yielded even more and other interesting information about CCR development.

In families at high psychosocial risk many families dropped out early due to difficulties completing forms and following instructions because of the negative impact of psychosocial conditions. The number of subjects attending Hagadal yearly are limited and they are hard to recruit for research due to their general psychosocial burden. Furthermore, during the study-period of infants at high psychosocial risk the Hagadal attachment program faced demands on cuts in resources. Due to this fact the rating according to Ainsworth sensitivity scale was not be prioritized leading to a reduced number of study subjects ( $\mathrm{n}=14$ dyads out of 25 possible). Also an additional control group in relation to the Hagadal attachment program, would have brought higher reliance to the result. Considering that all families at high psychosocial risk are highly dependent on professional care, a non-treated control group would create a considerable ethical dilemma since the program is already established as a routine. One could perhaps compare the Hagadal attachment program with another treatment somewhere else but these populations and other possible differences in treatment conditions would be cumbersome.

As pointed out above, the relatively small number of subjects in paper IV is a limitation. The crossover design partially compensates for this problem. In addition a possible effect of oral glucose as an intervention was difficult to completely evaluate since NPS did not produce a stress/pain response. 
LIMITATIONS 


\section{ACKNOWLEDGEMENTS}

My gratitude goes out to all those who have contributed to the work leading to this thesis. In particular, I would like to thank:

All Infants and Parents participating in the studies.

My supervisors, our work together under your guidance has led to these publications on which my thesis stands.

My main supervisor Professor Nina Nelson-Follin, for your patience and trust in me and this project. For sharing your knowledge and guiding me through this research process, for thoughtful advice and constructive criticism, for making this happen and believing in me.

-But above all, for being a part of my life, through thick and thin, words are not enough...

My co-supervisor Associated Professor Evalotte Mörelius, for your enthusiasm, patience and generosity. For company and support in Glasgow and in the lab.

My co-supervisor Professor Annette Theodorsson, for introducing me to the researchworld.

Associated Professor Mats Fredrikson, for invaluable statistical guidance and assistance.

My co-authors Orvar Finnström for valuable discussions and for shearing clinical experiences, Elvar Theodorsson for introducing and guiding me through the laboratory work, Per A Gustafsson for valuable discussions and for shearing clinical experiences essential for this thesis as well as arouse my interest for child psychiatry, and Jakob $\mathbf{O}$ Ström for valuable statistical advises.

I would also like to thank research nurse Christina Fuxin invaluable work with data collection, filing and administration but above all, laughter and support. 
Psychologist Lena Blom for invaluable knowledge about Hagadal, help and support.

Lisbeth $\mathbf{H j a ̈ l l e ~ f o r ~ i n t r o d u c i n g ~ a n d ~ t e a c h i n g ~ m e d ~ t h e ~ R I A ~ a n a l y s e s ~ a n d ~ f o r ~ y o u r ~ a n d ~ A n n a ~}$ Pfister's skilled highly reliable work with RIA analyses.

I would also like to thank the following healthcare professionals: Jenny Eriksson and Irja Väinämö at Linköping University Hospital; Karin Fridolfsson, Anna Granath, Maria Ström, Eva Bolin and Dr. Fredrik Ingemansson at Ryhov Hospital in Jönköping; Catharina Gustavsson, family counsellor and Gunilla Hellström, family counsellor at Hagadal daycare center and Therese Sjöström, Christine Rosén, Jane Vanky, Anne Sandehed and Helena Lüning for technical assistance, for their excellent work in recruiting families, teaching parents saliva sampling and collecting questionnaires.

I would like to thank my great colleges and friends at "Gula Villan" for all help and support as well as nice coffee breaks, interesting discussions and most importantly a lot of laughter; Karin, Lina, Lasse, Nora, Helen, Mats, Lotta, Malin and Eva.

I would also like to thank my colleges and friends Åshild, Martina and the staff at "Labettan" for help and support in the laboratory, as well as nice coffee-breaks and laughter.

Last but not least, To my friends and family - Without you I would not be standing here!!!

I would like to thank...

My “extra” co-supervisor Cecilia Halling-Linder, words are not enough... For all guidance, help and support with the thesis!!! Your upcoming $\mathrm{PhD}$ students will be the luckiest!! For laughter and truths, but above all true friendship. 
Jessica Larsson Viksten for an amazing friendship, endless talks, dragging me out on walks, your endless patience with me and above all your fearless kindhearted straightforwardness.

Fredrik Viksten for technical assistance with computers... for interesting discussions, dinners and for being such a good supportive friend.

Annika Carney for an amazing friendship, love and support and for always being there for me and my family.

Åsa Monemar for helping me keep perspective on life, and being my friend.

My parents: Gunbritt and Anders Ivars, Thank you for your endless love and support, for always believing in me, all help, patience and you being you!! Without you I would not be here!!

Mikaela, my loving, beautiful, amazing sister for you being you!

Victor and Pontus - You are simply my everything!!

\section{Jonas,}

-I love you! -for you being YOU! And loving me for being ME...

Simply for us being US... Together!! 
ACKNOWLEDGEMENTS 


\section{REFERENCES}

1. Barker, D.J., Fetal growth and adult disease. Br J Obstet Gynaecol, 1992. 99(4): p. 275-6.

2. Barker, D.J. and C.N. Martyn, The maternal and fetal origins of cardiovascular disease. J Epidemiol Community Health, 1992. 46(1): p. 8-11.

3. Barker, D.J., The fetal origins of adult hypertension. J Hypertens Suppl, 1992. 10(7): p. S3944.

4. Hovi, P., et al., Intima-media thickness and flow-mediated dilatation in the Helsinki study of very low birth weight adults. Pediatrics, 2011. 127(2): p. e304-11.

5. Leon, D.A., et al., Reduced fetal growth rate and increased risk of death from ischaemic heart disease: cohort study of 15000 Swedish men and women born 1915-29. BMJ, 1998. 317(7153): p. 241-5.

6. Hales, C.N., et al., Fetal and infant growth and impaired glucose tolerance at age 64. BMJ, 1991. 303(6809): p. 1019-22.

7. Zhang, Z., P.M. Kris-Etherton, and T.J. Hartman, Birth weight and risk factors for cardiovascular disease and type 2 diabetes in US children and adolescents: 10 year results from NHANES. Matern Child Health J, 2014. 18(6): p. 1423-32.

8. Barker, D.J., The developmental origins of insulin resistance. Horm Res, 2005. 64 Suppl 3: p. 2-7.

9. Hovi, P., et al., Ambulatory blood pressure in young adults with very low birth weight. J Pediatr, 2010. 156(1): p. 54-59 e1.

10. McNamara, B.J., et al., Early life influences on cardio-metabolic disease risk in aboriginal populations--what is the evidence? A systematic review of longitudinal and case-control studies. Int J Epidemiol, 2012. 41(6): p. 1661-82.

11. Johansson, S., et al., Risk of high blood pressure among young men increases with the degree of immaturity at birth. Circulation, 2005. 112(22): p. 3430-6.

12. Hovi, P., et al., Glucose regulation in young adults with very low birth weight. $\mathrm{N}$ Engl J Med, 2007. 356(20): p. 2053-63.

13. Kaijser, M., et al., Perinatal risk factors for diabetes in later life. Diabetes, 2009. 58(3): p. 5236.

14. Crump, C., et al., Gestational age at birth and mortality in young adulthood. JAMA, 2011. 306(11): p. 1233-40.

15. Koupil, I., D.A. Leon, and H.O. Lithell, Length of gestation is associated with mortality from cerebrovascular disease. J Epidemiol Community Health, 2005. 59(6): p. 473-4.

16. Finnstrom, O., et al., The Swedish national prospective study on extremely low birthweight (ELBW) infants. Incidence, mortality, morbidity and survival in relation to level of care. Acta Paediatr, 1997. 86(5): p. 503-11.

17. Group, E., et al., One-year survival of extremely preterm infants after active perinatal care in Sweden. JAMA, 2009. 301(21): p. 2225-33.

18. Karagiannis, T.C. and N. Maulik, Factors influencing epigenetic mechanisms and related diseases. Antioxid Redox Signal, 2012. 17(2): p. 192-4.

19. Fradin, D. and P. Bougneres, T2DM: Why Epigenetics? J Nutr Metab, 2011. 2011: p. 647514.

20. Suter, M., et al., Maternal tobacco use modestly alters correlated epigenome-wide placental DNA methylation and gene expression. Epigenetics, 2011. 6(11): p. 1284-94.

21. Talens, R.P., et al., Hypermethylation at loci sensitive to the prenatal environment is associated with increased incidence of myocardial infarction. Int J Epidemiol, 2012. 41(1): p. 106-15.

22. Wu, G., et al., Maternal nutrition and fetal development. J Nutr, 2004. 134(9): p. 2169-72.

23. Brenseke, B., et al., Current thoughts on maternal nutrition and fetal programming of the metabolic syndrome. J Pregnancy, 2013. 2013: p. 368461. 
24. Rogers, J.M., Tobacco and pregnancy: overview of exposures and effects. Birth Defects Res C Embryo Today, 2008. 84(1): p. 1-15.

25. Wikstrom, A.K., et al., Effect of Swedish snuff (snus) on preterm birth. BJOG, 2010. 117(8): p. 1005-10.

26. Knight, A.K. and A.K. Smith, Epigenetic Biomarkers of Preterm Birth and Its Risk Factors. Genes (Basel), 2016. 7(4).

27. Lindblom, R., et al., The early life origin theory in the development of cardiovascular disease and type 2 diabetes. Mol Biol Rep, 2015. 42(4): p. 791-7.

28. Lundqvist, E., K. Gottvall, and K. Källén, Health and Medical Care; Pregnancies, Deliveries and Newborn Infants; The Swedish Medical Birth Register 1973-2014, Assisted Reproduction, treatment 1991-2013. . 2015, The National Board of Health and Welfare (Socialstyrelsen): Stockholm.

29. Bolt, R.J., et al., Maturity of the adrenal cortex in very preterm infants is related to gestational age. Pediatr Res, 2002. 52(3): p. 405-10.

30. Murphy, B.E., Cortisol and cortisone in human fetal development. J Steroid Biochem, 1979. 11(1B): p. 509-13.

31. Hillman, N.H., S.G. Kallapur, and A.H. Jobe, Physiology of transition from intrauterine to extrauterine life. Clin Perinatol, 2012. 39(4): p. 769-83.

32. Crowley, P., I. Chalmers, and M.J. Keirse, The effects of corticosteroid administration before preterm delivery: an overview of the evidence from controlled trials. Br J Obstet Gynaecol, 1990. 97(1): p. 11-25.

33. Dalziel, S.R., et al., Antenatal exposure to betamethasone: psychological functioning and health related quality of life 31 years after inclusion in randomised controlled trial. BMJ, 2005. 331(7518): p. 665.

34. Stevens, B.J., et al., Epidemiology and management of painful procedures in children in Canadian hospitals. CMAJ, 2011. 183(7): p. E403-10.

35. Johnston, C., et al., Pain in Canadian NICUs: have we improved over the past 12 years? Clin J Pain, 2011. 27(3): p. 225-32.

36. Anand, K.J., Clinical importance of pain and stress in preterm neonates. Biol Neonate., 1998. 73(1): p. 1-9.

37. Owens, R., Intraventricular hemorrhage in the premature neonate. Neonatal Netw, 2005. 24(3): p. 55-71.

38. McEwen, B.S. and J.C. Wingfield, The concept of allostasis in biology and biomedicine. Horm Behav., 2003. 43(1): p. 2-15.

39. Lagercrantz, H., Hjärnans utveckling, in Neonatologi, H. Lagercrantz, L. Hellström-Westas, and M. Norman, Editors. 2008, Studentlitteratur: Lund.

40. Padilla, N., et al., Brain Growth Gains and Losses in Extremely Preterm Infants at Term. Cereb Cortex, 2015. 25(7): p. 1897-905.

41. Peterson, B.S., et al., Regional brain volume abnormalities and long-term cognitive outcome in preterm infants. JAMA, 2000. 284(15): p. 1939-47.

42. Soria-Pastor, S., et al., Decreased regional brain volume and cognitive impairment in preterm children at low risk. Pediatrics, 2009. 124(6): p. e1161-70.

43. Kikusui, T. and Y. Mori, Behavioural and neurochemical consequences of early weaning in rodents. J Neuroendocrinol, 2009. 21(4): p. 427-31.

44. Ono, M., et al., Early weaning induces anxiety and precocious myelination in the anterior part of the basolateral amygdala of male Balb/c mice. Neuroscience, 2008. 156(4): p. 1103-10.

45. Becker, K., et al., Exposure to neonatal separation stress alters exploratory behavior and corticotropin releasing factor expression in neurons in the amygdala and hippocampus. Dev Neurobiol, 2007. 67(5): p. 617-29. 
46. Mehta, M.A., et al., Amygdala, hippocampal and corpus callosum size following severe early institutional deprivation: the English and Romanian Adoptees study pilot. J Child Psychol Psychiatry, 2009. 50(8): p. 943-51.

47. Tottenham, N. and M.A. Sheridan, A review of adversity, the amygdala and the hippocampus: a consideration of developmental timing. Front Hum Neurosci, 2009. 3: p. 68.

48. McEwen, B.S., Neurobiology of interpreting and responding to stressful events: paradigmating role of the hippocampus in Handbock of physiology. Section 7 The endocrine system

B.S. McEwen, Editor. 2001, Oxford University Press Inc: New York.

49. Morelius, E., H.G. He, and S. Shorey, Salivary Cortisol Reactivity in Preterm Infants in Neonatal Intensive Care: An Integrative Review. Int J Environ Res Public Health, 2016. 13(3).

50. Sapolsky, R.M., The possibility of neurotoxicity in the hippocampus in major depression: $a$ primer on neuron death. Biol Psychiatry., 2000. 48(8): p. 755-65.

51. Sapolsky, R.M., Depression, antidepressants, and the shrinking hippocampus. Proc Natl Acad Sci U S A., 2001. 98(22): p. 12320-2.

52. Kirschbaum, C. and D.H. Hellhammer, Salivary cortisol in psychobiological research: an overview. Neuropsychobiology, 1989. 22(3): p. 150-69.

53. Hellhammer, D.H., S. Wust, and B.M. Kudielka, Salivary cortisol as a biomarker in stress research. Psychoneuroendocrinology, 2009. 34(2): p. 163-71.

54. Edwards, S., et al., Exploration of the awakening cortisol response in relation to diurnal cortisol secretory activity. Life Sci, 2001. 68(18): p. 2093-103.

55. Giannakoulopoulos, X., et al., Fetal plasma cortisol and beta-endorphin response to intrauterine needling. Lancet., 1994. 344(8915): p. 77-81.

56. McEwen, B., The end of stress as we know it. 2002, Washington: Joseph Henry Press.

57. Buckingham, J.C., Glucocorticoids: exemplars of multi-tasking. Br J Pharmacol, 2006. 147 Suppl 1: p. S258-68.

58. Gunnar, M.R., Studies of the human infant's adrenocortical response to potentially stressful events. New Dir Child Dev, 1989(45): p. 3-18.

59. Kristenson, M., P. Garvin, and U. Lundberg, The Role of Saliva Cortisol Measurement in Health and Disease, M. Kristenson, Editor. 2011, Bentham Science Publishers.

60. Gallagher, T.F., et al., ACTH and cortisol secretory patterns in man. J Clin Endocrinol Metab, 1973. 36(6): p. 1058-68.

61. Price, D.A., G.C. Close, and B.A. Fielding, Age of appearance of circadian rhythm in salivary cortisol values in infancy. Arch Dis Child, 1983. 58(6): p. 454-6.

62. Spangler, G., The emergence of adrenocortical circadian function in newborns and infants and its relationship to sleep, feeding and maternal adrenocortical activity. Early Hum Dev, 1991. 25(3): p. 197-208.

63. Kiess, W., et al., Salivary cortisol levels throughout childhood and adolescence: relation with age, pubertal stage, and weight. Pediatr Res, 1995. 37(4 Pt 1): p. 502-6.

64. Lewis, M. and D.S. Ramsay, Developmental change in infants' responses to stress. Child Dev, 1995. 66(3): p. 657-70.

65. Santiago, L.B., S.M. Jorge, and A.C. Moreira, Longitudinal evaluation of the development of salivary cortisol circadian rhythm in infancy. Clin Endocrinol (Oxf), 1996. 44(2): p. 157-61.

66. de Weerth, C., R.H. Zijl, and J.K. Buitelaar, Development of cortisol circadian rhythm in infancy. Early Hum Dev, 2003. 73(1-2): p. 39-52.

67. Custodio, R.J., et al., The emergence of the cortisol circadian rhythm in monozygotic and dizygotic twin infants: the twin-pair synchrony. Clin Endocrinol (Oxf), 2007. 66(2): p. 192-7.

68. Jett, P.L., et al., Variability of plasma cortisol levels in extremely low birth weight infants. J Clin Endocrinol Metab, 1997. 82(9): p. 2921-5.

69. Kidd, S., et al., Lack of adult-type salivary cortisol circadian rhythm in hospitalized preterm infants. Horm Res, 2005. 64(1): p. 20-7. 
70. Antonini, S.R., S.M. Jorge, and A.C. Moreira, The emergence of salivary cortisol circadian rhythm and its relationship to sleep activity in preterm infants. Clin Endocrinol (Oxf), 2000. 52(4): p. 423-6.

71. Dorn, F., et al., Influence of acoustic stimulation on the circadian and ultradian rhythm of premature infants. Chronobiol Int, 2014. 31(9): p. 1062-74.

72. Economou, G., et al., Cortisol secretion in stressed babies during the neonatal period. Horm Res, 1993. 40(5-6): p. 217-21.

73. Scott, S.M. and K.L. Watterberg, Effect of gestational age, postnatal age, and illness on plasma cortisol concentrations in premature infants. Pediatr Res, 1995. 37(1): p. 112-6.

74. Vermes, I., et al., Maturation of the circadian rhythm of the adrenocortical functions in human neonates and infants. Horm Res, 1980. 12(5): p. 237-44.

75. Wadsby, M., G. Sydsjo, and C.G. Svedin, Evaluation of an intervention programme to support mothers and babies at psychosocial risk: assessment of mother/child interaction and mother's perceptions of benefit. Health Soc Care Community, 2001. 9(3): p. 125-33.

76. Lupien, S.J., et al., Larger amygdala but no change in hippocampal volume in 10-year-old children exposed to maternal depressive symptomatology since birth. Proc Natl Acad Sci U S A, 2011. 108(34): p. 14324-9.

77. Levine, S. and S.G. Wiener, Psychoendocrine aspects of mother-infant relationships in nonhuman primates. Psychoneuroendocrinology, 1988. 13(1-2): p. 143-54.

78. Huot, R.L., et al., Foster litters prevent hypothalamic-pituitary-adrenal axis sensitization mediated by neonatal maternal separation. Psychoneuroendocrinology, 2004. 29(2): p. 27989.

79. Gruss, M., et al., Maternal separation during a specific postnatal time window prevents reinforcement of hippocampal long-term potentiation in adolescent rats. Neuroscience, 2008. 152(1): p. 1-7.

80. Liu, D., et al., Maternal care, hippocampal glucocorticoid receptors, and hypothalamicpituitary-adrenal responses to stress. Science, 1997. 277(5332): p. 1659-62.

81. Sanchez, M.M., C.O. Ladd, and P.M. Plotsky, Early adverse experience as a developmental risk factor for later psychopathology: evidence from rodent and primate models. Dev Psychopathol, 2001. 13(3): p. 419-49.

82. Andersen, S.L. and M.H. Teicher, Delayed effects of early stress on hippocampal development. Neuropsychopharmacology, 2004. 29(11): p. 1988-93.

83. Luecken, L.J., Childhood attachment and loss experiences affect adult cardiovascular and cortisol function. Psychosom Med, 1998. 60(6): p. 765-72.

84. Nicolson, N.A., Childhood parental loss and cortisol levels in adult men. Psychoneuroendocrinology, 2004. 29(8): p. 1012-8.

85. Pruessner, J.C., et al., Dopamine release in response to a psychological stress in humans and its relationship to early life maternal care: a positron emission tomography study using [11C]raclopride. J Neurosci, 2004. 24(11): p. 2825-31.

86. Buss, C., et al., Maternal care modulates the relationship between prenatal risk and hippocampal volume in women but not in men. J Neurosci, 2007. 27(10): p. 2592-5.

87. Bremner, J.D., et al., Magnetic resonance imaging-based measurement of hippocampal volume in posttraumatic stress disorder related to childhood physical and sexual abuse--a preliminary report. Biol Psychiatry, 1997. 41(1): p. 23-32.

88. Stein, M.B., et al., Hippocampal volume in women victimized by childhood sexual abuse. Psychol Med, 1997. 27(4): p. 951-9.

89. Vythilingam, M., et al., Childhood trauma associated with smaller hippocampal volume in women with major depression. Am J Psychiatry, 2002. 159(12): p. 2072-80.

90. De Bellis, M.D., et al., A.E. Bennett Research Award. Developmental traumatology. Part II: Brain development. Biol Psychiatry, 1999. 45(10): p. 1271-84. 
91. De Bellis, M.D., et al., A pilot longitudinal study of hippocampal volumes in pediatric maltreatment-related posttraumatic stress disorder. Biol Psychiatry, 2001. 50(4): p. 305-9.

92. Woon, F.L. and D.W. Hedges, Hippocampal and amygdala volumes in children and adults with childhood maltreatment-related posttraumatic stress disorder: a meta-analysis. Hippocampus, 2008. 18(8): p. 729-36.

93. Lupien, S.J., et al., Child's stress hormone levels correlate with mother's socioeconomic status and depressive state. Biol Psychiatry, 2000. 48(10): p. 976-80.

94. Essex, M.J., et al., Maternal stress beginning in infancy may sensitize children to later stress exposure: effects on cortisol and behavior. Biol Psychiatry, 2002. 52(8): p. 776-84.

95. Halligan, S.L., et al., Disturbances in morning cortisol secretion in association with maternal postnatal depression predict subsequent depressive symptomatology in adolescents. Biol Psychiatry, 2007. 62(1): p. 40-6.

96. Ashman, S.B., et al., Stress hormone levels of children of depressed mothers. Dev Psychopathol, 2002. 14(2): p. 333-49.

97. Ainsworth, M.D.S., et al., Patterns of attachment: A psychological study of the strange situation. Lawrence Erlbaum Associates, Hillsdale NJ, USA., 1978.

98. Nachmias, M., et al., Behavioral inhibition and stress reactivity: the moderating role of attachment security. Child Dev, 1996. 67(2): p. 508-22.

99. Spangler, G. and K.E. Grossmann, Biobehavioral organization in securely and insecurely attached infants. Child Dev, 1993. 64(5): p. 1439-50.

100. de Weerth, C., J.K. Buitelaar, and R. Beijers, Infant cortisol and behavioral habituation to weekly maternal separations: links with maternal prenatal cortisol and psychosocial stress. Psychoneuroendocrinology, 2013. 38(12): p. 2863-74.

101. Saridjan, N.S., et al., Do social disadvantage and early family adversity affect the diurnal cortisol rhythm in infants? The Generation R Study. Horm Behav, 2010. 57(2): p. 247-54.

102. Simons, S.S., et al., Development of the cortisol circadian rhythm in the light of stress early in life. Psychoneuroendocrinology, 2015. 62: p. 292-300.

103. van der Vegt, E.J., et al., Early childhood adversities and trajectories of psychiatric problems in adoptees: evidence for long lasting effects. J Abnorm Child Psychol, 2009. 37(2): p. 239-49.

104. McEwen, B.S. and R.M. Sapolsky, Stress and cognitive function. Curr Opin Neurobiol., 1995. 5(2): p. 205-16.

105. Sapolsky, R.M., L.M. Romero, and A.U. Munck, How do glucocorticoids influence stress responses? Integrating permissive, suppressive, stimulatory, and preparative actions. Endocr Rev., 2000. 21(1): p. 55-89.

106. Vitaliano, P.P., et al., A path model of chronic stress, the metabolic syndrome, and coronary heart disease. Psychosom Med, 2002. 64(3): p. 418-35.

107. Grunau, R.E., et al., Neonatal pain, parenting stress and interaction, in relation to cognitive and motor development at 8 and 18 months in preterm infants. Pain, 2009. 143(1-2): p. 13846.

108. Lombroso, P.J. and R. Sapolsky, Development of the cerebral cortex: XII. Stress and brain development: I. J Am Acad Child Adolesc Psychiatry, 1998. 37(12): p. 1337-9.

109. Haley, D.W., J. Weinberg, and R.E. Grunau, Cortisol, contingency learning, and memory in preterm and full-term infants. Psychoneuroendocrinology, 2006. 31(1): p. 108-17.

110. Quesada, A.A., et al., Hyper-responsiveness to acute stress, emotional problems and poorer memory in former preterm children. Stress, 2014. 17(5): p. 389-99.

111. Wadsby, M., et al., Behaviour problems and cortisol levels in very-low-birth-weight children. Nord J Psychiatry, 2014. 68(8): p. 626-32.

112. Hiramatsu, R., Direct assay of cortisol in human saliva by solid phase radioimmunoassay and its clinical applications. Clin Chim Acta, 1981. 117(2): p. 239-49. 
113. Mörelius, E., N. Nelson, and E. Theodorsson, Salivary cortisol and administration of concentrated oral glucose in newborn infants: improved detection limit and smaller sample volumes without glucose interference. Scand J Clin Lab Invest., 2004. 64(2): p. 113-8.

114. Mörelius, E., N. Nelson, and E. Theodorsson, Saliva collection using cotton buds with wooden sticks: a note of caution. Scand J Clin Lab Invest., 2006. 66(1): p. 15-8.

115. Kristenson, M., Impact of socioeconomic determinants on psychosocial factors and lifestyle-for health service: the Swedish experience. Soc Sci Med, 2012. 74(5): p. 661-4.

116. Garde, A.H. and A.M. Hansen, Long-term stability of salivary cortisol. Scand J Clin Lab Invest, 2005. 65(5): p. 433-6.

117. Clements, A.D. and C.R. Parker, The relationship between salivary cortisol concentrations in frozen versus mailed samples. Psychoneuroendocrinology, 1998. 23(6): p. 613-6.

118. Aardal, E. and A.C. Holm, Cortisol in saliva--reference ranges and relation to cortisol in serum. Eur J Clin Chem Clin Biochem, 1995. 33(12): p. 927-32.

119. Mörelius, E., et al., Is a nappy change stressful to neonates? Early Hum Dev., 2006. 82(10): p. 669-76.

120. Mörelius, E., E. Theodorsson, and N. Nelson, Salivary cortisol and mood and pain profiles during skin-to-skin care for an unselected group of mothers and infants in neonatal intensive care. Pediatrics., 2005. 116(5): p. 1105-13.

121. Mörelius, E., N. Nelson, and P.A. Gustafsson, Salivary cortisol response in mother-infant dyads at high psychosocial risk. Child Care Health Dev., 2007. 33(2): p. 128-36.

122. Kleberg, A., et al., Lower stress responses after Newborn Individualized Developmental Care and Assessment Program care during eye screening examinations for retinopathy of prematurity: a randomized study. Pediatrics, 2008. 121(5): p. e1267-78.

123. Magnano, C.L., J.M. Gardner, and B.Z. Karmel, Differences in salivary cortisol levels in cocaine-exposed and noncocaine-exposed NICU infants. Dev Psychobiol, 1992. 25(2): p. 93103.

124. Davis, E.P., et al., Effects of prenatal betamethasone exposure on regulation of stress physiology in healthy premature infants. Psychoneuroendocrinology, 2004. 29(8): p. 102836.

125. Candia, M.F., et al., Influence of prone positioning on premature newborn infant stress assessed by means of salivary cortisol measurement: pilot study. Rev Bras Ter Intensiva, 2014. 26(2): p. 169-75.

126. Schwilling, D., et al., Live music reduces stress levels in very low-birthweight infants. Acta Paediatr, 2015. 104(4): p. 360-7.

127. Gustafsson, P.E., N. Nelson, and P.A. Gustafsson, Diurnal cortisol levels, psychiatric symptoms and sense of coherence in abused adolescents. Nord J Psychiatry, 2010. 64(1): p. 27-31.

128. Yehuda, R., Psychoneuroendocrinology of post-traumatic stress disorder. Psychiatr Clin North Am, 1998. 21(2): p. 359-79.

129. Lambers, D.S. and K.E. Clark, The maternal and fetal physiologic effects of nicotine. Semin Perinatol, 1996. 20(2): p. 115-26.

130. Pomerleau, O.F., Nicotine and the central nervous system: biobehavioral effects of cigarette smoking. Am J Med, 1992. 93(1A): p. 2S-7S.

131. McDonald, S.D., et al., The effect of tobacco exposure on the fetal hypothalamic-pituitaryadrenal axis. BJOG, 2006. 113(11): p. 1289-95.

132. Bruner, J.P. and I. Forouzan, Smoking and buccally administered nicotine. Acute effect on uterine and umbilical artery Doppler flow velocity waveforms. J Reprod Med, 1991. 36(6): p. 435-40.

133. Spangler, G., et al., The specificity of infant emotional expression for emotion perception. Int J Psychophysiol, 2001. 41(2): p. 155-68. 
134. Grossmann, K., et al., Maternal sensitivity and newborns' orientation responses as related to quality of attachment in northern Germany. Monogr Soc Res Child Dev, 1985. 50(1-2): p. 233-56.

135. Spangler, G., Psychological and physiological responses during an exam and their relation to personality characteristics. Psychoneuroendocrinology, 1997. 22(6): p. 423-41.

136. Ainsworth, M.S.D., S.M. Bell, and D.J. Stayton, Mother-infant attachment and social development:'socialisation' as a product of reciprocal responsivenss to signals. The integration of a child into a social world. Cambridge University Press, Cambridge, England., 1974: p. 99-135.

137. Main, M. and J. Solomon, Procedures for identifying infants as disorganized/disorientated during the Ainsworth Strange Situation. In M. T. Greenberg, D. Cicchetti \& E. M. Cummings (Eds.), Attachment in the preschool years: Theory, research and intervention, 1990: p. 121160.

138. Sydsjo, G., M. Wadsby, and C.G. Svedin, Life development for 20 pairs of children with and without psychosocial problems--a 16-year-long study with follow-up. Nord J Psychiatry, 2007. 61(1): p. 19-26.

139. Wadsby, M., C.G. Svedin, and G. Sydsjo, Children of mothers at psychosocial risk growing up: a follow up at the age of 16. J Adolesc, 2007. 30(1): p. 147-64.

140. Svedin, C.G., M. Wadsby, and G. Sydsjo, Mental health, behaviour problems and incidence of child abuse at the age of 16 years. A prospective longitudinal study of children born at psychosocial risk. Eur Child Adolesc Psychiatry, 2005. 14(7): p. 386-96.

141. Wadsby, M., G. Sydsjo, and C.G. Svedin, Children of psychosocial risk-mothers: life events, social interaction, and behaviour problems at the age of 8 years. Scand J Soc Med, 1996. 24(4): p. 227-36.

142. Svedin, C.G., M. Wadsby, and G. Sydsjo, Children of mothers who are at psycho-social risk. Mental health, behaviour problems and incidence of child abuse at age 8 years. Eur Child Adolesc Psychiatry, 1996. 5(3): p. 162-71.

143. Rutter, M. and D. Quinton, Parental psychiatric disorder: effects on children. Psychol Med, 1984. 14(4): p. 853-80.

144. Rutter, M., Psychosocial influences: critiques, findings, and research needs. Dev Psychopathol, 2000. 12(3): p. 375-405.

145. Belsky, J. and R.M. Fearon, Infant-mother attachment security, contextual risk, and early development: a moderational analysis. Dev Psychopathol, 2002. 14(2): p. 293-310.

146. Als, H., A synactive model of neonatal behavioral organization: framework for the assessment of neurobehavioral development in the premature infant and for support of infants and parents in the neonatal intensive care environment. Physical \& Occupational Therapy in Pediatrics, 1986. 6(3): p. 3-53.

147. Als, H., Developmental care in the newborn intensive care unit. Curr Opin Pediatr., 1998. 10(2): p. 138-42.

148. Als, H., et al., Early experience alters brain function and structure. Pediatrics., 2004. 113(4): p. 846-57.

149. Als, H., et al., Individualized behavioral and environmental care for the very low birth weight preterm infant at high risk for bronchopulmonary dysplasia: neonatal intensive care unit and developmental outcome. Pediatrics., 1986. 78(6): p. 1123-32.

150. Als, H., et al., The Brazelton Neonatal Behavioral Assessment Scale (BNBAS). J Abnorm Child Psychol., 1977. 5(3): p. 215-31.

151. Boyer, K., et al., Does sucrose analgesia promote physiologic stability in preterm neonates? Biol Neonate, 2004. 85(1): p. 26-31.

152. Xiaomei, C., S.M. Ludington-Hoe, and S. Walsh, Randomized crossover trial of kangaroo care to reduce biobehavioral pain responses in preterm infants: a pilot study. Biol Res Nurs, 2011. 13(2): p. 204-16. 
153. Cignacco, E., et al., Variability in pain response to a non-pharmacological intervention across repeated routine pain exposure in preterm infants: a feasibility study. Acta Paediatr, 2009. 98(5): p. 842-6.

154. Cong, X., S.M. Ludington-Hoe, and S. Walsh, Randomized crossover trial of kangaroo care to reduce biobehavioral pain responses in preterm infants: a pilot study. Biol Res Nurs, 2011. 13(2): p. 204-16.

155. Badiee, Z., M. Asghari, and M. Mohammadizadeh, The calming effect of maternal breast milk odor on premature infants. Pediatr Neonatol, 2013. 54(5): p. 322-5.

156. Badiee, Z., Z. Nassiri, and A. Armanian, Cobedding of twin premature infants: calming effects on pain responses. Pediatr Neonatol, 2014. 55(4): p. 262-8.

157. Campbell-Yeo, M.L., et al., Co-bedding between preterm twins attenuates stress response after heel lance: results of a randomized trial. Clin J Pain, 2014. 30(7): p. 598-604.

158. Watterberg, K.L. and S.M. Scott, Evidence of early adrenal insufficiency in babies who develop bronchopulmonary dysplasia. Pediatrics, 1995. 95(1): p. 120-5.

159. Fernandez, E.F. and K.L. Watterberg, Relative adrenal insufficiency in the preterm and term infant. J Perinatol, 2009. 29 Suppl 2: p. S44-9.

160. Grunau, R.E., et al., Altered basal cortisol levels at 3, 6, 8 and 18 months in infants born at extremely low gestational age. J Pediatr., 2007. 150(2): p. 151-6.

161. Brummelte, S., et al., Cortisol levels in former preterm children at school age are predicted by neonatal procedural pain-related stress. Psychoneuroendocrinology, 2015. 51: p. 151-63.

162. Grunau, R.E., J. Weinberg, and M.F. Whitfield, Neonatal procedural pain and preterm infant cortisol response to novelty at 8 months. Pediatrics., 2004. 114(1): p. e77-84.

163. Holsti, L., et al., Relationships between adrenocorticotropic hormone and cortisol are altered during clustered nursing care in preterm infants born at extremely low gestational age. Early Hum Dev, 2007. 83(5): p. 341-8.

164. Grunau, R.E., et al., Neonatal procedural pain exposure predicts lower cortisol and behavioral reactivity in preterm infants in the NICU. Pain., 2005. 113(3): p. 293-300.

165. Barker, D.P. and N. Rutter, Exposure to invasive procedures in neonatal intensive care unit admissions. Arch Dis Child Fetal Neonatal Ed., 1995. 72(1): p. F47-8.

166. Cignacco, E., et al., Pain assessment in the neonate using the Bernese Pain Scale for Neonates. Early Hum Dev, 2004. 78(2): p. 125-31.

167. Anand, K.J., Consensus statement for the prevention and management of pain in the newborn. Arch Pediatr Adolesc Med, 2001. 155(2): p. 173-80.

168. Mokhnach, L., et al., NICU procedures are getting sweeter: development of a sucrose protocol for neonatal procedural pain. Neonatal Netw, 2010. 29(5): p. 271-9.

169. Skogsdahl, Y.E., M. Schollin, J, Analgesia in newborns given oral glucose. Acta Paediatr., 1996. 86: p. 217-220.

170. Eriksson, M. and M. Gradin, Pain management in Swedish neonatal units--a national survey. Acta Paediatr, 2008. 97(7): p. 870-4.

171. Harrison, D., et al., Analgesic effects of sweet-tasting solutions for infants: current state of equipoise. Pediatrics, 2010. 126(5): p. 894-902.

172. Morelius, E., E. Theodorsson, and N. Nelson, Stress at three-month immunization: parents' and infants' salivary cortisol response in relation to the use of pacifier and oral glucose. Eur J Pain, 2009. 13(2): p. 202-8.

173. Engle, W.A., F. American Academy of Pediatrics Committee on, and Newborn, Age terminology during the perinatal period. Pediatrics, 2004. 114(5): p. 1362-4.

174. Ainsworth, M.D., Patterns of infant-mother attachments: antecedents and effects on development. Bull N Y Acad Med, 1985. 61(9): p. 771-91.

175. Gitau, R., et al., Fetal exposure to maternal cortisol. Lancet., 1998. 352(9129): p. 707-8.

176. Stahl, F., P. Amendt, and G. Dorner, Total and free cortisol plasma levels in pre-and postnatal life. Endokrinologie., 1979. 74(2): p. 243-6. 
177. Nelson, N., K. Arbring, and E. Theodorsson, Neonatal salivary cortisol in response to heelstick: method modifications enable analysis of low concentrations and small sample volumes. Scand J Clin Lab Invest, 2001. 61(4): p. 287-91.

178. Morelius, E., N. Nelson, and E. Theodorsson, Salivary cortisol and administration of concentrated oral glucose in newborn infants: improved detection limit and smaller sample volumes without glucose interference. Scand J Clin Lab Invest, 2004. 64(2): p. 113-8.

179. Hagekull, B., The Baby and Toddler Behavior Questionnaires: Empirical studies and conceptual considerations Scandinavian Journal of Psychology, 1985(26): p. 110-122.

180. Greenwald, R. and A. Rubin, Assessment of posttraumatic symptoms in children: Development and preliminary validation of parent and child scales. . Research on Social Work Practice, 1999. 9: p. 61-75.

181. Gustafsson, P.E., et al., Sociocultural disadvantage, traumatic life events, and psychiatric symptoms in preadolescent children. Am J Orthopsychiatry, 2009. 79(3): p. 387-97.

182. Pederson, D.R., et al., Maternal sensitivity and the security of infant-mother attachment: a Q-sort study. Child Dev, 1990. 61(6): p. 1974-83.

183. De Wolff, M.S. and M.H. van ljzendoorn, Sensitivity and attachment: a meta-analysis on parental antecedents of infant attachment. Child Dev, 1997. 68(4): p. 571-91.

184. Miljkovitch, R., et al., Maternal interactive behaviour as a predictor of preschoolers' attachment representations among full term and premature samples. Early Hum Dev, 2013. 89(5): p. 349-54.

185. The CRIB (clinical risk index for babies) score: a tool for assessing initial neonatal risk and comparing performance of neonatal intensive care units. The International Neonatal Network. Lancet, 1993. 342(8865): p. 193-8.

186. Reid, S., et al., Comparing CRIB-II and SNAPPE-II as mortality predictors for very preterm infants. J Paediatr Child Health, 2014.

187. Luria, R.E., The validity and reliability of the visual analogue mood scale. J Psychiatr Res, 1975. 12(1): p. 51-7.

188. Pruessner, J.C., et al., Two formulas for computation of the area under the curve represent measures of total hormone concentration versus time-dependent change. Psychoneuroendocrinology, 2003. 28(7): p. 916-31.

189. Wilder, J., The law of initial value in neurology and psychiatry; facts and problems. J Nerv Ment Dis, 1957. 125(1): p. 73-86.

190. Helbock, H.J., R.M. Insoft, and F.A. Conte, Glucocorticoid-responsive hypotension in extremely low birth weight newborns. Pediatrics, 1993. 92(5): p. 715-7.

191. Tollenaar, M.S., et al., Cortisol in the first year of life: normative values and intra-individual variability. Early Hum Dev, 2010. 86(1): p. 13-6.

192. Holditch-Davis, D., et al., Sleeping and waking state development in preterm infants. Early Hum Dev, 2004. 80(1): p. 43-64.

193. Salomonsson, B., Psychdynamic therapies with infants and parents: A critical review of treatment methods. Psychodynamic Psychiatry, 2014. 42(2): p. 203-234.

194. Rutter, M., How the environment affects mental health. Br J Psychiatry, 2005. 186: p. 4-6.

195. Spangler, G., Individual dispositions as precursors of differences in attachment quality: why maternal sensitivity is nevertheless important. Attach Hum Dev, 2013. 15(5-6): p. 657-72.

196. Schieche, M. and G. Spangler, Individual differences in biobehavioral organization during problem-solving in toddlers: the influence of maternal behavior, infant-mother attachment, and behavioral inhibition on the attachment-exploration balance. Dev Psychobiol, 2005. 46(4): p. 293-306.

197. Holsti, L. and R.E. Grunau, Considerations for using sucrose to reduce procedural pain in preterm infants. Pediatrics, 2010. 125(5): p. 1042-7.

198. Bettendorf, M., et al., Longitudinal evaluation of salivary cortisol levels in full-term and preterm neonates. Horm Res, 1998. 50(6): p. 303-8. 


\section{REFERENCES}

199. Tarnow-Mordi, W. and A. Mitra, Postnatal dexamethasone in preterm infants is potentially lifesaving, but follow up studies are urgently needed. BMJ, 1999. 319(7222): p. 1385-6.

200. Sampson, M.R., D.K. Benjamin, and M. Cohen-Wolkowiez, Evidence-based guidelines for pediatric clinical trials: focus on StaR Child Health. Expert Rev Clin Pharmacol, 2012. 5(5): p. 525-31.

201. Franck, L.S., Research with newborn participants: doing the right research and doing it right. J Perinat Neonatal Nurs, 2005. 19(2): p. 177-86.

202. Simons, S.H., et al., Routine morphine infusion in preterm newborns who received ventilatory support: a randomized controlled trial. JAMA., 2003. 290(18): p. 2419-27.

203. Schepp, K.G., Factors influencing the coping effort of mothers of hospitalized children. Nurs Res, 1991. 40(1): p. 42-6.

204. Ivars, K., et al., Correction: Development of Salivary Cortisol Circadian Rhythm and Reference Intervals in Full-Term Infants. PLoS One, 2016. 11(3): p. e0151888. 


\section{APPENDIX (PAPERS I - IV)}





\section{Papers}

The articles associated with this thesis have been removed for copyright reasons. For more details about these see:

http://urn.kb.se/resolve?urn=urn:nbn:se:liu:diva-127498 